University of Redlands

\title{
Design for Water Quality Index Mapping Tool for Kuyalnik Liman, Ukraine
}

\author{
A Major Individual Project submitted in partial satisfaction of the requirements \\ for the degree of Master of Science in Geographic Information Systems \\ by \\ Anton Sizo \\ Douglas Flewelling, Ph.D., Committee Chair \\ Mark Kumler, Ph.D.
}

August 2010 
Design of Water Quality Index Mapping Tool for Kuyalnik Liman, Ukraine

Copyright (C) 2010

by

Anton Sizo 
The report of Anton Sizo is approved.

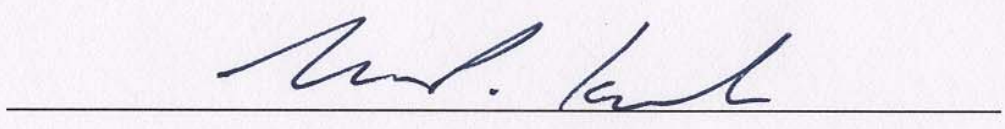

Mark Kumler, Ph.D.

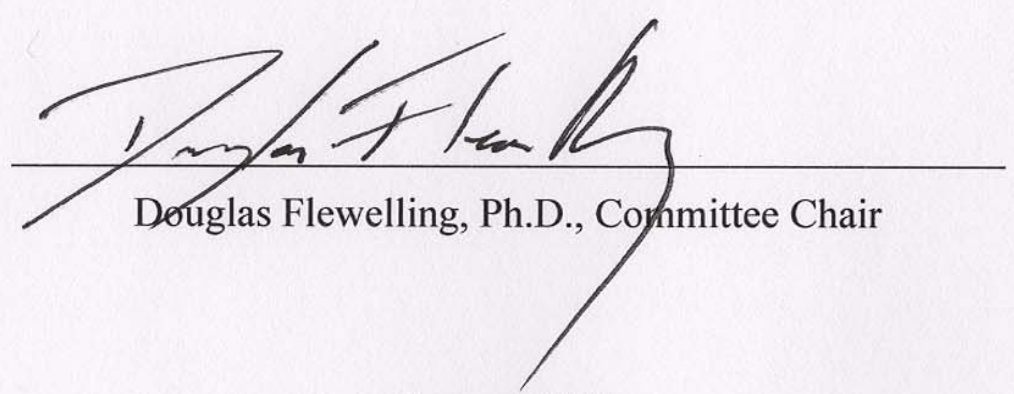

August 2010 



\section{Acknowledgements}

This MS GIS Program was really challenging for me and I want to thank people who helped me and who made this year at the University of Redlands possible.

I would like to thank the Morrison family and the Fulbright Scholarship foundation for the opportunity to study and to live here in Redlands. I also want to mention International Friendship Connection - the organization that introduced me to American traditions and helped me to get accustomed here.

I want to thank the faculty and staff in the MS GIS program, especially Douglas Flewelling, my advisor, for his being and Mark Kumler, my second reader, for his "good touch" method of map evaluation. And I want to give a credit to Debbie Riley and Ruben Ortiz for support during the whole program - they spiritedly managed all problems I provoked.

And there is no way that I could have gotten through this program without support of my family and my friends - here and in Ukraine. 



\author{
Abstract \\ Design of Water Quality Index Mapping Tool for Kuyalnik Liman, Ukraine \\ by \\ Anton Sizo
}

Kuyalnik Salt Lake (local name - Kuyalnik Liman) is of great importance for Ukraine because of its recreational and natural resources (medicinal mud and mineral water) and balneology spa network.

Because of its location near a large industrial and port city, the liman is under permanent anthropogenic influence that negatively impacts the fragile ecosystem of Kuyalnik Liman as well as the neighboring area. Because of the significance of the liman for Ukraine, it requires continual environmental monitoring of the liman area including monitoring its water quality.

This project designed and implemented a set of tools for water quality mapping based on the hydro-chemical index of water pollution. It combined both processing the data from water sample analysis with methods of spatial analysis for the lake. This tool will serve to help specialists in the environmental monitoring of Kuyalnik Liman area. 



\section{Table of Contents}

Chapter 1 - Introduction $\quad 1$

1.1 Client 1

1.2 Problem Statement 1

1.3 Proposed Solution 2

1.3.1 Goals and Objectives 2

1.3.2 Scope 2

1.3.3 Methods 2

1.4 Audience 3

1.5 Overview of the Rest of this Report 3

Chapter 2 - Background and Literature Review 5

2.1 Kuyalnik Liman $\quad 5$

$\begin{array}{lll}2.2 & \text { WQI Approach } & 7\end{array}$

2.3 Water Quality Modeling and GIS Framework in Environmental Assessment 8

$\begin{array}{lll}2.4 & \text { Summary } & 9\end{array}$

Chapter 3 - Systems Analysis and Design $\quad 11$

$\begin{array}{lll}3.1 & \text { Problem Statement } & 11\end{array}$

$\begin{array}{lll}3.2 & \text { Requirements Analysis } & 11\end{array}$

3.2.1 Functional Requirements 11

$\begin{array}{lll}3.2 .2 & \text { Technical Requirements } & 11\end{array}$

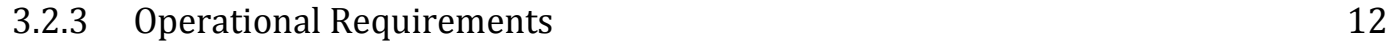

3.2.4 Transitional Requirements 12

$\begin{array}{lll}3.3 & \text { System Design } & 12\end{array}$

$\begin{array}{lll}3.3 .1 & \text { Map } & 13\end{array}$

$\begin{array}{lll}3.3 .2 & \text { Technology } & 14\end{array}$

$\begin{array}{lll}\text { 3.3.3 System architecture } & 16\end{array}$

$\begin{array}{lll}\mathbf{3 . 4} \text { Project Plan } & \mathbf{1 7}\end{array}$

$\begin{array}{ll}3.4 .1 \text { Challenges } & 17\end{array}$

$\begin{array}{lll}3.4 .2 & \text { Budget } & 17\end{array}$

$\begin{array}{lll}3.4 .3 & \text { Deliverables } & 18\end{array}$

$\begin{array}{lll}3.4 .4 & \text { Risks } & 18\end{array}$

$\begin{array}{lll}3.5 & \text { Summary } & 18\end{array}$

Chapter 4 - Database Design $\quad 19$

$\begin{array}{lll}4.1 & \text { Conceptual Database Design } & 19\end{array}$

\begin{tabular}{ll}
4.2 & Database Implementation \\
\hline
\end{tabular}

4.3 Data Sources and Data Collection Methods 21

4.4 Data Scrubbing and Loading 22

$\begin{array}{lll}4.5 & \text { Summary } & 23\end{array}$

Chapter 5 - Implementation $\quad 25$

5.1 The Method of WQI calculation 25

$\begin{array}{lll}5.2 & \text { Workflow of the WQI calculation } & 28\end{array}$

Chapter 6 - Results and Analysis $\quad 39$

6.1 The Geodatabase and the Water Quality Index tool 39

$\begin{array}{lll}6.2 & \text { Tool Application } & 39\end{array}$ 
Chapter 7 - Conclusions and Future Projects 43

$\begin{array}{lll}7.1 & \text { Conclusions } & 43\end{array}$

$\begin{array}{lll}7.2 & \text { Future projects } & \mathbf{4 4}\end{array}$

7.2.1 Web resource 44

7.2.2 GIS framework for water quality assessment with set of water quality tools 45

$\begin{array}{ll}\text { Works Cited } & 47\end{array}$

Appendix A. The tables of the geodatabase structure classes 49

Appendix B. The listing of the WQI tool Python code 54

Appendix C. The copy of WQI methodology in original (Russian) language 63 


\section{Table of Figures}

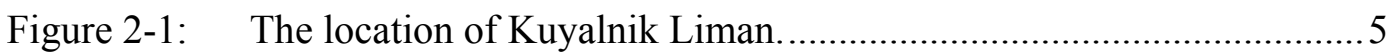

Figure 2-2: Main consumers of the water quality information................................ 6

Figure 2-3: The water sampling station network.............................................

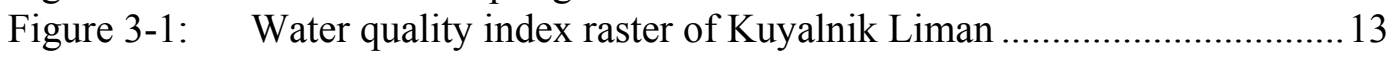

Figure 3-2: The layers of water quality of Kuyalnik Liman................................. 14

Figure 3-3: GUI window for the water quality index tool ................................ 15

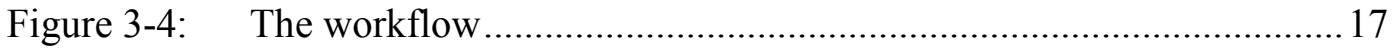

Figure 4-1: The database conceptual design....................................................20

Figure 4-2: The hardcopy of Kuyalnik Liman bathymetry, northern part............22

Figure 4-3: The data for the bathymetry data processing...................................2

Figure 5-1: $\quad$ MPC relationship to biochemical oxygen demand level. ..................26

Figure 5-2: $\quad$ Ci/MPCi relationship to dissolved oxygen level...............................2. 26

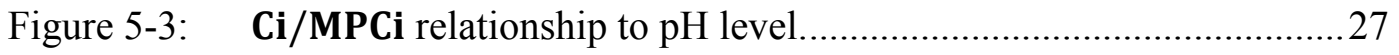

Figure 5-4: The algorithm of the WQI tool by main functions. ...........................28

Figure 5-5: The service variable input tool GUI..................................................2. 29

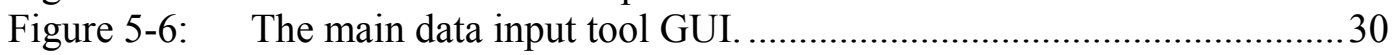

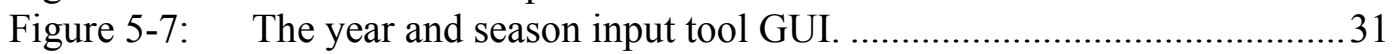

Figure 5-8: The shoreline calculation and output raster tool GUI........................ 31

Figure 5-9: The WQI tool properties dialog window GUI.................................... 38

Figure 5-10: The input view of save a source table parameter................................38

Figure 6-1: Year and season input in the WQI toolset GUI ................................40

Figure 7-1: The example of water quality web resource for Kuyalnik Liman.....45 



\section{List of Tables}

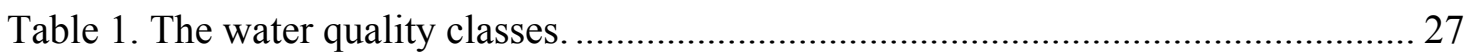

Table A-1. Table of water samples parameters. ........................................................... 49

Table A-2. Table of maximum permissible concentrations......................................... 50

Table A-3. Feature class of water monitoring stations. .................................................. 51

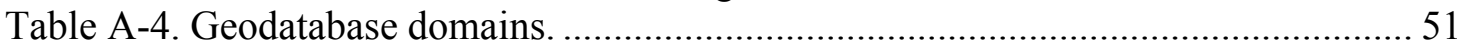

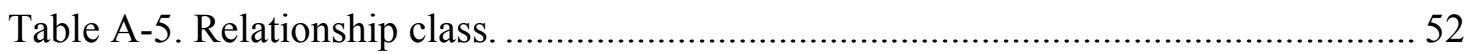

Table A-6. The specification of the water pond elevation class...................................... 53 



\section{List of Acronyms and Definitions}

$\begin{array}{ll}\text { WQI } & \text { Water quality index } \\ \text { GIS } & \text { Geographic information system } \\ \text { DEM } & \text { Digital elevation model } \\ \text { IDW } & \text { Inverse distance weighted } \\ \text { SWAT } & \text { Soil and Water Assessment Tool } \\ \text { MPC } & \text { Maximum permissible concentrations } \\ \text { BES } & \text { Baltic Elevation System } \\ \text { GUI } & \text { Graphical user interface }\end{array}$





\section{Chapter 1 - Introduction}

Kuyalnik Liman is an inland salt lake located in the south of Ukraine. The liman is the largest source of unique medicinal sulfide-silt mud, mineral water, and chloridehydrocarbonate-sodic-magnesium healing brine. Because the liman is economically important to the country, permanent environmental monitoring of the Kuyalnik Liman area is required, which includes monitoring water quality.

The client's department, as a representative of the public research institution, is responsible for monitoring environmental changes in the Kuyalnik Liman area. The calculation of the water quality index (WQI) is part of the environmental assessment of the current condition of the liman. The client needs a geographical information system (GIS) to automate the WQI calculation process.

\subsection{Client}

The client for this project was Shikhaleeva Galina, Head of The Environment Monitoring Department, from the Institute of Physics and Chemistry for Environment and Human Protection.

The main activities of the Environmental Monitoring Department include addressing environmental pollution issues (in air and water, soil and plants), writing white papers for governmental organizations on environmental topics, supporting public organizations in decision making in environmental management, and conducting education and research activities.

The Environmental Monitoring Department, as a representative of the institution, conducts the public project "Complex Environmental Assessment of Natural Resource and Recreation Potential of the Basin of Kuyalnik Liman". For this project, the client is responsible for monitoring environmental changes in the area of Kuyalnik Liman. Annual and seasonal reports, as well as occasional white papers, require the client to calculate the WQI, and to produce charts illustrating the current environmental condition of Kuyalnik Liman. The client needed a GIS tool to automate the WQI calculation process and to map the WQI spatial distribution.

\subsection{Problem Statement}

The client needed a GIS solution that could support the environmental monitoring process of Kuyalnik Liman in terms of mapping of water quality.

The client wanted a WQI tool that automates the routine calculation of WQI and provides a map of the spatial distribution of WQI through the liman area. The shoreline of the resulting raster should show the water level for the research time period of WQI calculation.

The method should be applicable to the area of interest, and should spread to the academic and administrative communities in Ukraine. 


\subsection{Proposed Solution}

This chapter describes the design of the WQI mapping tool for GIS support of the Environment Monitoring Department for the project of environmental assessment of Kuyalnik Liman. It shows the principal scheme of the WQI tool and the necessary data.

\subsubsection{Goals and Objectives}

The client needed GIS support to automate the WQI calculation process and to map the WQI spatial distribution. The strategic steps for the project were: to define the method of WQI calculation; implement the method in the GIS procedure; and produce a map of the WQI.

The challenging issue with the first step was to define methodology for the WQI calculation. Different methods entail the use of different scales of water quality. These results can cause confusion in preparing white papers and may cause a mistake in a decision-making process. So, space and time analyses that are based on different kinds of water quality assessment might be wrong. Choosing one appropriate method for the area of research, and its implementation as a GIS procedure, will allow the client to avoid routine manual calculation of the WQI, and will use a standard system for data collection that serves as a foundation for decision making.

The second issue has to do with data manipulation. The client wanted to present the current water quality of Kuyalnik Liman as a raster dataset. The client needed raster data for spatial analysis. It was very important to choose an appropriate method of WQI interpolation for the irregular network of the water monitoring stations. Since the Kuyalnik Liman is a shallow water body that greatly depends on rain and snowfall levels, it is necessary to consider that Kuyalnik's water level changes significantly within the course of a year.

\subsubsection{Scope}

The project implementation included four principal sections: the calculation of the water quality index (WQI), the mapping of the spatial distribution of the WQI, data preparation, and database design.

The project involved the use of a standard method of calculation. A needs assessment was conducted to determine which methodology to use, how to use and organize a geodatabase (the results of water analysis, the data about place and time of water sampling, the data of the water level). Spatial mapping of the WQI was based on bathymetry data of Kuyalnik Liman and the location of water sampling stations.

\subsubsection{Methods}

The chosen WQI calculation methodology compares the maximum permissible concentration of pollutants and the current concentration of pollution in the water body (State Committee of Hydrometeorology of the USSR (1986)).

To implement the WQI calculation within a GIS, a geodatabase was designed to contain the water analysis results table and the location of the water monitoring stations. For these purposes a list of pollutants, possible ranges of concentrations, and the layer 
with the disposition of the water monitoring stations were used. The methodology of the WQI calculation mentioned above gave formulas for calculation. Python was used as a programming and scripting language in the ArcGIS environment.

The change of the liman water level was shown in the raster of the WQI spatial distribution as a shoreline. This required using the Spatial Analysis tools and bathymetry data of the Kuyalnik Liman bottom.

The inverse distance weighted (IDW) interpolation method was chosen as an appropriate method for estimating the WQI for the irregular network of water monitoring stations. The IDW interpolation was proposed to and approved by the client.

\subsection{Audience}

This report was prepared for an audience qualified in the environment monitoring sphere, well educated (no less then Bachelor or Specialist degree in natural science), preferably with experience in chemical or environmental field and with a basis in statistic analysis. The audience should be experienced in GIS software at no less then at user level.

The audience might also include personnel from environmental or chemical laboratories, students or professors from academic institutions affiliated to natural sciences or studies, and employees of NGO's or public organizations who are involved in environmental management.

\subsection{Overview of the Rest of this Report}

Chapter 2 will provide information about the general context of Kuyalnik Liman and the bordering area. Also there are the basis of the report problem and an overview of existing similar situations and implemented solutions: different approaches in WQI calculation and GIS applications for water quality, etc.

Chapter 3 describes the project system analysis and design. There are functional and technical requirements for the WQI tool implementation at workplace, operational and transitional requirements for tool maintenance and installment for workflow.

Chapter 4 describes all database design decisions that were made during the project: conceptual and logical models of support geodatabase of water sampling and the WQI tool; description of data source of maps for bathymetry data of Kuyalnik Liman and methods of map and table data preparation.

Chapter 5 discusses the project implementation. It answers the question "How was it created?" through the Python code and ArcGIS geoprocessing.

The project results discussion and analysis are in Chapter 6; answers for the questions: "Did the client get what he wants?", "Was the project implemented as it was planned?", "Was it challenging?".

Chapter 7 shows connection between implemented project and future plans and opportunities. Different water quality methods that could be realized, environment of the WQI tool implementation, and such other topics are discussed there. 



\section{Chapter 2 - Background and Literature Review}

The geographic disposition of Kuyalnik Liman and its morphological features make the environmental conditions of this lake highly dependent on climate and anthropogenic impact. This situation raises a question about permanent environmental monitoring, methods and approaches appropriate to environmental assessment of the liman. GIS framework provides an adequate basis for data analysis and processing, and WQI gives a method for relevant rating of the liman's water quality.

\subsection{Kuyalnik Liman}

Kuyalnik Salt Lake (locally - Kuyalnik Liman) is located in the south of Ukraine (Figure 2-1) and is affiliated with a group of northwest Black Sea littoral limans.

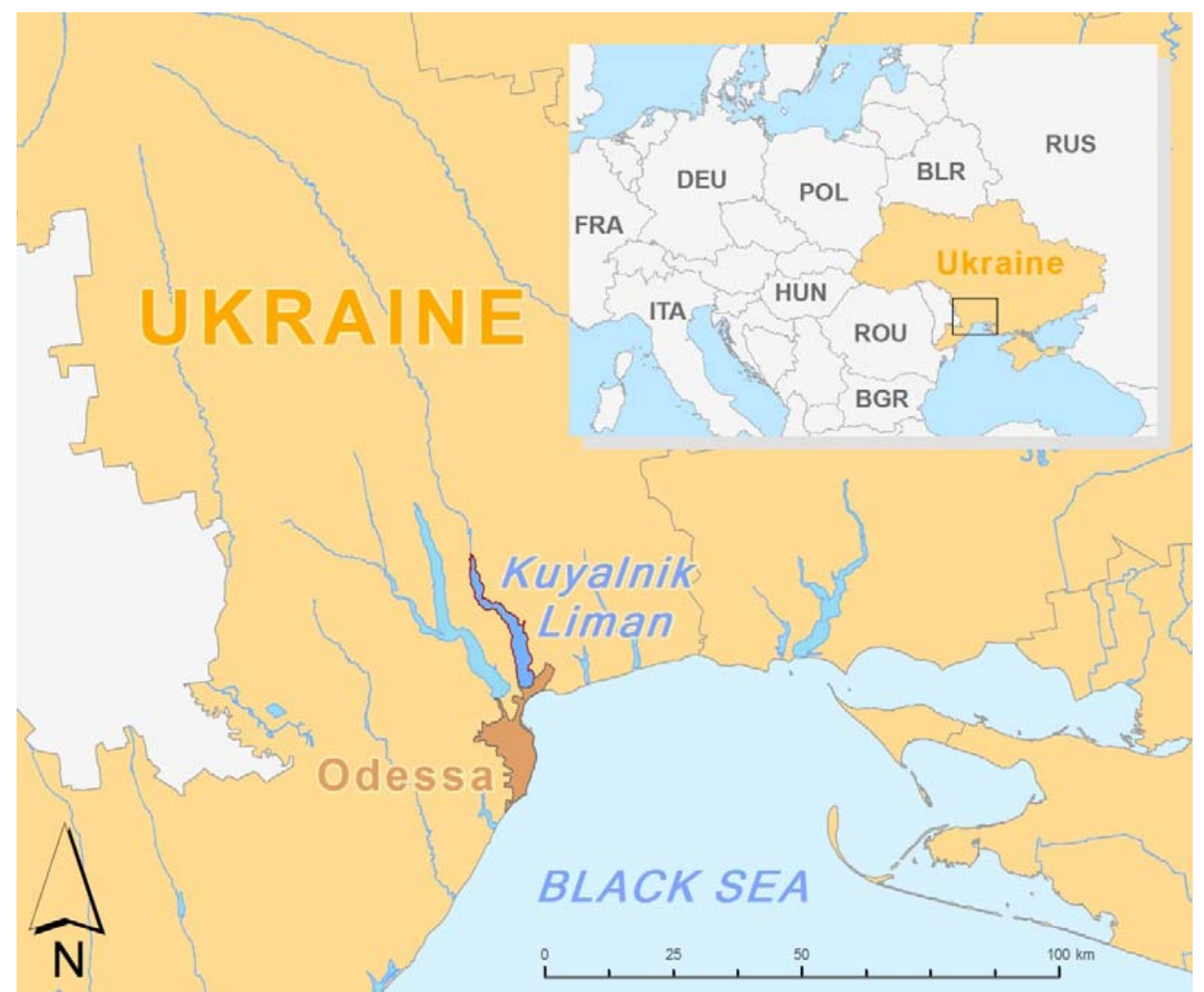

Figure 2-1: The location of Kuyalnik Liman.

The watershed area of Kuyalnik Liman is 2250 square $\mathrm{km}$. The morphological parameters are highly dependent on annual precipitation, but on average the water area is 56 square $\mathrm{km}$, the length is $25 \mathrm{~km}$, the width is $2.2 \mathrm{~km}$ and the depth may reach $4.5 \mathrm{~m}$ (Timchenko, 1990).

The main resources drawn from Kuyalnik Liman are 23848 thousand cubic meters of medicinal sulfide-silt mud, 1385 cubic meters per day of mineral water (Cabinet of 
Ministry of Ukraine, 1996), and up to 112 million cubic meters of chloridehydrocarbonate-sodic-magnesium healing brine in the bowl of the liman.

Kuyalnik Liman is situated near the city of Odessa (population one million) with a broad network of balneological spas. The oldest spa has been there for about 170 years. The unique location of Kuyalnik Liman - its proximity to the Black Sea, sandy beaches, and healthy prairie air - make the region around Kuyalnik Liman a significant balneological health resort with unique natural conditions.

Kuyalnik Liman is a water body with a limited water cycle, and it is significantly impacted by human activities in the city of Odessa. The shallow depth and long length of the liman also make it sensitive to the climatic condition of the region, hydrological conditions, and water quality.

Because of its importance to Ukraine, permanent environmental monitoring of the area of Kuyalnik Liman is required, which includes the monitoring of water quality and keeping different parties informed (Figure 2-2).

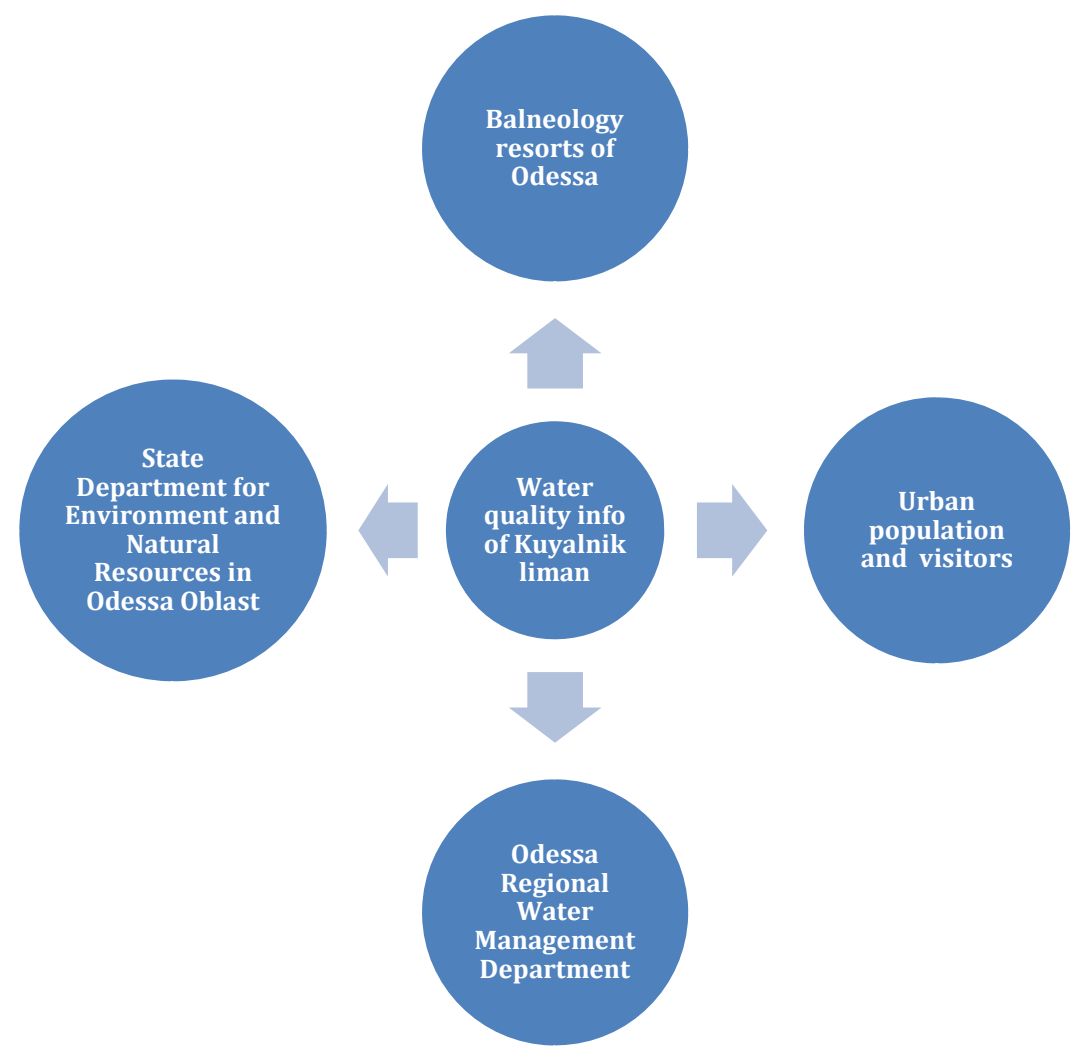

Figure 2-2: Main consumers of the water quality information.

Processed by the client, the environmental monitoring scheme is seasonally based. The locations of the water sampling stations are irregular through the liman area (Figure 2-3).

The client, as the research institution, is responsible for monitoring environmental changes in the area of Kuyalnik Liman. Annual and seasonal reports, as well as occasional white papers, require the client to manually calculate the WQI and present the current condition of Kuyalnik Liman with charts. The client wanted to avoid manual 
routine calculation of WQI and create a mechanism to present the distribution of WQI in a spatial continuum with ability to use the data for spatial and temporal analysis.

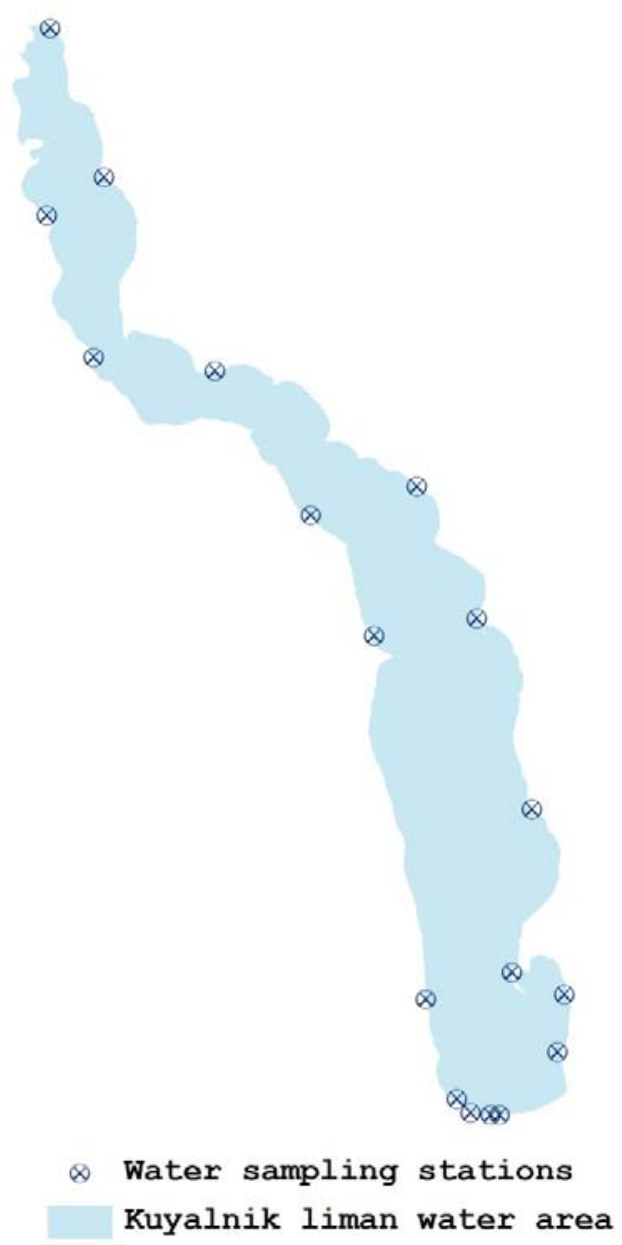

Figure 2-3: The water sampling station network.

\subsection{WQI Approach}

Nature conservation organizations, both administrative and research oriented, use various approaches to calculate WQI. The quality index calculation method depends mainly on state affiliation, geographic location of water bodies, type of water use, chemical, and biological factors. Therefore, the determination of WQI calculation is crucial in mapping water quality for a specific water body.

The Canadian Council of Ministers of the Environment (2001) and Stoner (1978), described the main purposes of using WQI: to unify the rating scale of natural water by using the meaningful water range from "very bad" to "very good", and for understanding of the water quality topics by non-specialists. Proposed by the Canadian Council of Ministers of the Environment (2001), the universal method of WQI calculation is based on three attributes of water quality: proportion of guideline values exceeded, frequency 
with which guideline values are exceeded, and magnitude by which guideline values are exceeded. These all depend on the levels of several parameters.

Cude (2001) proposed a method of WQI calculation, applicable for certain carefully studied water objects. In his case, it is a method used by the state of Oregon in the US. He recorded values for eight measureable variables of water quality when they were beyond a certain range: temperature, dissolved oxygen, biochemical oxygen demand, $\mathrm{pH}$, ammonia + nitrate nitrogen, total phosphorus, total solids, and fecal coliform. A similar method was also used by Hambright et al. (2000). However, their selected variables and ranges are only applicable for Lake Kinneret (Sea of Galilee), Israel.

A wide range of methods for WQI calculation have been inherited from soviet research institutions in the countries of the former Soviet Republic. Shitiokov et al. (2003) proposed several methods of WQI calculation based on hydro-chemical variables of assessment of water quality, such as:

- Parameter of chemical water pollution, calculated on the basis exceeding limits of 10 water parameters

- Combinatorial index of pollution, based on limits exceeding, multiplicity and its frequency

- Method from the Science Research Institution for Hygiene of F.F. Erisman, that takes into account exceeding levels of chemical, microbe, and organoleptic parameters

Currently, the commonly used method of WQI determination in Ukraine is the method proposed by State Committee of Hydrometeorology of the USSR (1986). It represents an average fraction of limits exceeding six parameters. These might be water parameters: biological oxygen demand, $\mathrm{O}_{2}, \mathrm{pH}$ and/or pollutants that are specific for study area. Because of their applicability to Kuyalnik Liman and popularity in Ukraine, this method was chosen as the theoretical base for this project.

\subsection{Water Quality Modeling and GIS Framework in Environmental Assessment}

Water quality modeling is a way to obtain information in case of lack of data, impossibility for direct research, or for forecasting. For example, the Federal Maritime and Hydrographic Agency of Germany routinely used a model of the condition of the North and Baltic Seas. The model considered water level, temperature, and salinity (Wright et al., 2007). The United States Environmental Protection Agency (2009) proposed different kinds of tools and models for various environmental issues, including schemas for water quality modeling: Water Quality Analysis Simulation Program v.7 (WASP7) and River and Stream Water Quality Model (QUAL2K).

In any case, any model requires an environment of implementation. And very often GIS serve not only as platforms for model development, but also as analysis and performance toolsets for spatial data. The ArcHydro Data Model for ArcGIS may serve as example. It is a spatial-temporal model for water resources, focusing on the modeling of the hydrological process of surface water and on hydrography. It includes components such as: network, drainage, channel, hydrography, and time series (Maidment, 2002). It requires customization based on the area of interest. Another example, Srinivasan at el. (1993) connected a tool kit for environmental pollution modeling Soil and Water 
Assessment Tool (SWAT) with OpenSource GIS. The system assists with management of runoff, erosion, pesticide, and nutrient movement in large scale basins. Zhang (2008) designed a GIS system that is a dynamic-based model which allows users to track water quality changes in rivers in one dimension for water pollution accidents. However, models and tools of water modeling are often designed for a specific water object or particular problem.

Kurakina et al. (2006) used the ArcGIS 9.1 environment for issue similar to the current project: they used Model Builder to create a tool for a WQI calculation for section of a river between water quality checkpoints. In this work, the authors also demonstrated using geo statistical methods for selection of method of interpolation.

Widely known ArcGIS 9.3.1 ESRI software was used for the current project as the environment for data store and transformation, as well as for the scripting environment. Python was selected as OpenSource language for coding.

\subsection{Summary}

Using GIS to address environmental issues is not a new approach. It has been widely used in the context of monitoring water quality. Essentially, water quality can be evaluated based on a water quality index that takes various forms. Using the WQI approach, water quality can be further modeled in a GIS platform.

For the current project the method of WQI calculation proposed by State Committee of Hydrometeorology of the USSR (1986) was used. ESRI ArcGIS 9.3.1 software was chosen as the GIS environment for tool development. 



\section{Chapter 3 - Systems Analysis and Design}

\subsection{Problem Statement}

The client for this project was Shikhaleeva Galina, Head of The Environmental Monitoring Department, from the Institute of Physics and Chemistry for Environment and Human Protection.

Kuyalnik Liman is a coastal salt lake located in the south of Ukraine. The liman is the source of medicinal sulfide-silt mud, mineral water, and chloride-hydrocarbonatesodic-magnesium healing brine. Because the liman is important to the country, the permanent environment monitoring of the area of the Kuyalnik Liman is required, which includes monitoring water quality of the liman.

The public research institution that the client is affiliated with is responsible for monitoring environmental changes in the area of Kuyalnik Liman. Annual and seasonal reports, as well as occasional white papers, require calculation by the client of WQI and the presentation of the current condition of the Kuyalnik Liman by charts. The client wanted to avoid manual routine calculation of WQI and needed a mechanism to present the distribution of WQI in a spatial continuum with ability to use the data for spatial and temporal analysis.

\subsection{Requirements Analysis}

\subsubsection{Functional Requirements}

The WQI mapping tool was developed for a research staff workplace. It is assumed that research personnel will use the WQI mapping tool for their workflow needs, in addition to current GIS software. The tool is designed for desktop operation, with user access to change data and save the result of his work.

\subsubsection{Technical Requirements}

The developed mapping tool works only in the ArcGIS environment. It is assumed that the user has valid ArcGIS Desktop and Spatial Analysis licenses (version 9.3). All necessary GIS data processing, data format exchanges, and updates are handled by ArcGIS software.

Hardware requirements:

\begin{tabular}{l|l}
\hline Platform & PC, Intel recommended \\
\hline CPU Speed & $1.6 \mathrm{GHz}$ recommended or higher \\
\hline Processor & Intel Core Duo, Pentium 4 or Xeon processors recommended \\
\hline Memory/RAM & $1 \mathrm{~GB}$ minimum, 2 GB recommended or higher. \\
\hline Display Properties & 24 bit color depth \\
\hline Screen Resolution & $1024 \times 768$ recommended or higher at Normal size (96dpi) \\
\hline Swap Space & Determined by the operating system, 500 MB minimum. \\
\hline Disk Space & 2.4 GB (at least 10 GB in case printing large maps) \\
\hline Video/Graphics Adapter & 24-bit capable graphics accelerator. An OpenGL 1.3 or higher compliant video card is
\end{tabular}


required, with at least $32 \mathrm{MB}$ of video memory, however $64 \mathrm{MB}$ of video memory or higher is recommended.

Networking Hardware

Media Player
Simple TCP/IP, Network Card or Microsoft Loopback Adapter is required for the License Manager.

DVD-ROM drive is required to install the application.

Software requirements:

- Windows Help program (WinHlp32.exe)

- .NET Framework 2.0 Requirement

- Internet Explorer (Version 7.0 or 8.0)

- Python

- Printer Support

\subsubsection{Operational Requirements}

The WQI mapping tool was supplied as a once-only delivery, as a ready-to-go tool. In the event of malfunctions, the information and developmental support is provided until the tool meets all requirements.

In case all technical requirements are met, there is no need for any additional maintenance for the tool. The ability of batch processing is included in the ArcGIS tool's features.

\subsubsection{Transitional Requirements}

The client's research personnel are highly qualified and well educated. They are used to working with complex data analysis software, and they have the necessary experience in the GIS field. Entrance training for this project was provided after the project was delivered.

The mapping tool was presented as an additional tool for research; minor changes of current client's workflow were implemented. To facilitate the alterations, the detailed description of changes in the business process was highlighted with instructor-led workshops. The migration from the previous workflow to the new one was also simplified by the complete tool technical help documentation that was the part of the delivery.

\subsection{System Design}

The calculation of WQI mapping tool was based on the method proposed by State Committee of Hydrometeorology of the USSR (1986). The parameters of water were obtained from laboratory analysis of samples from the water monitoring stations network of Kuyalnik Liman.

The WQI mapping tool was intended for use in ArcMap or ArcCatalog environment as a toolset. The output of the introduced tool was a map of the water quality index distribution in ArcGIS raster format, with possible use with any kind of map data presentation and analysis supported by ArcGIS. 


\subsubsection{Map}

The output map of the project tool was in digital format (ESRI grid raster dataset) and showed spatial distribution of the WQI through the Kuyalnik Liman area. The calculation methodology was proposed by State Committee of Hydrometeorology of the USSR (1986). The outline of the water quality raster reproduced the shape of the water body, based on the current water level (see Figure 3.1, year: 2008, water level: $-5.33 \mathrm{~m}$ in Baltic Elevation System (BES))

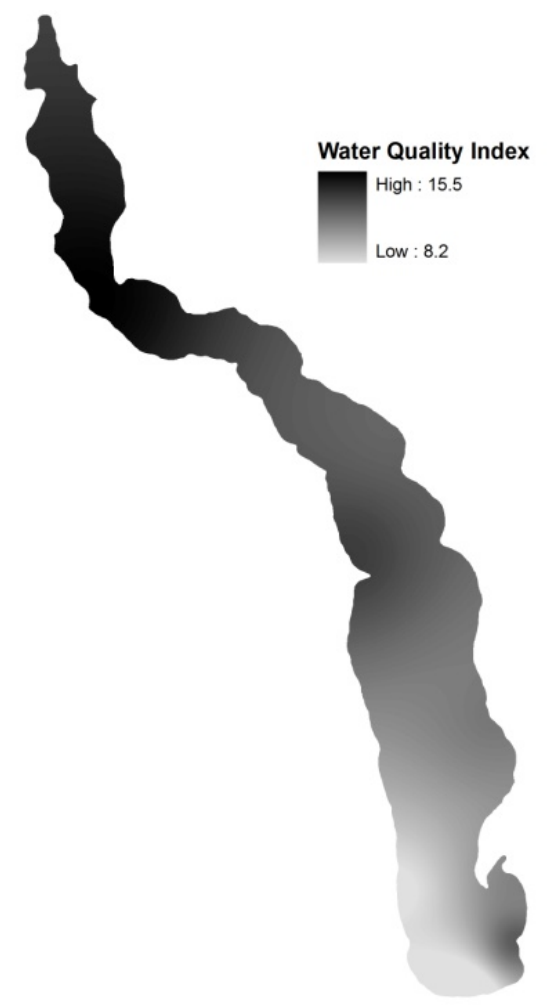

Figure 3-1: Water quality index raster of Kuyalnik Liman

For a support of map classification, the reference layer with symbology was included in the delivery. The layer divided the WQI raster into seven gradations of water quality:

\begin{tabular}{|l|c|}
\hline Water quality & Class of water quality \\
\hline Very clean & I \\
\hline Clean & II \\
\hline Moderately impure & III \\
\hline Impure & IV \\
\hline Polluted & V \\
\hline Very polluted & VI \\
\hline Extremely polluted & VII \\
\hline
\end{tabular}

Reference layer was represented in a color scheme, corresponding to the meaning of water quality differentiation: clean water was represented in positive colors (e.g. hues of 
green), polluted and impure water were represented in negative colors (e.g. hues of red), (Figure 3.2; $\mathrm{pH}, \mathrm{O}_{2}, \mathrm{~Pb}, \mathrm{Cd}, \mathrm{Cr}$, Nitrites were used for WQI calculation with MPC'c from Euro Union water standards).
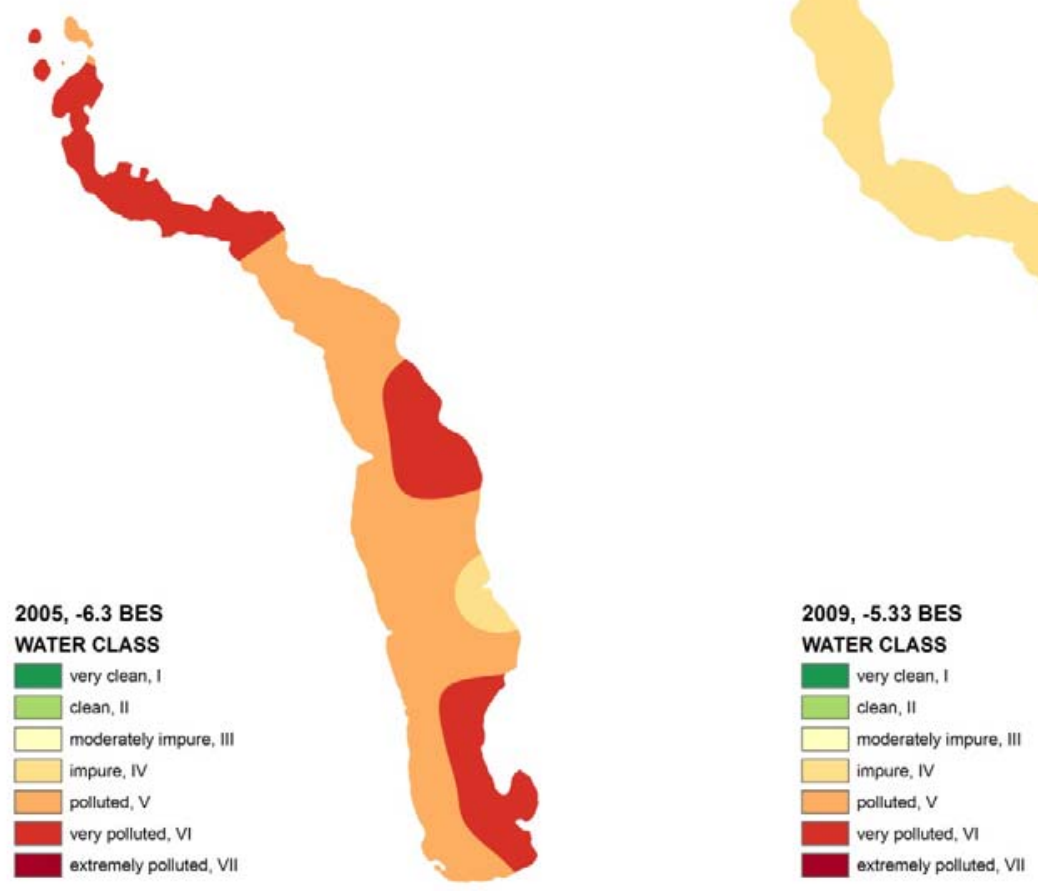

Figure 3-2: The layers of water quality of Kuyalnik Liman

\subsubsection{Technology}

The main part of the project delivery was represented as an ESRI ArcToolbox element. The user may work with the tool both from ArcMap and ArcCatalog environment. A graphic user interface (GUI) was designed by regular ArcGIS GUI form for geoprocessing tools (Figure 3.3).

The use of a regular ArcGIS GUI as a water quality index mapping tool lets the user be more familiar with the processes of tool operation. Included tool help assists the user in aspects of tool use. 


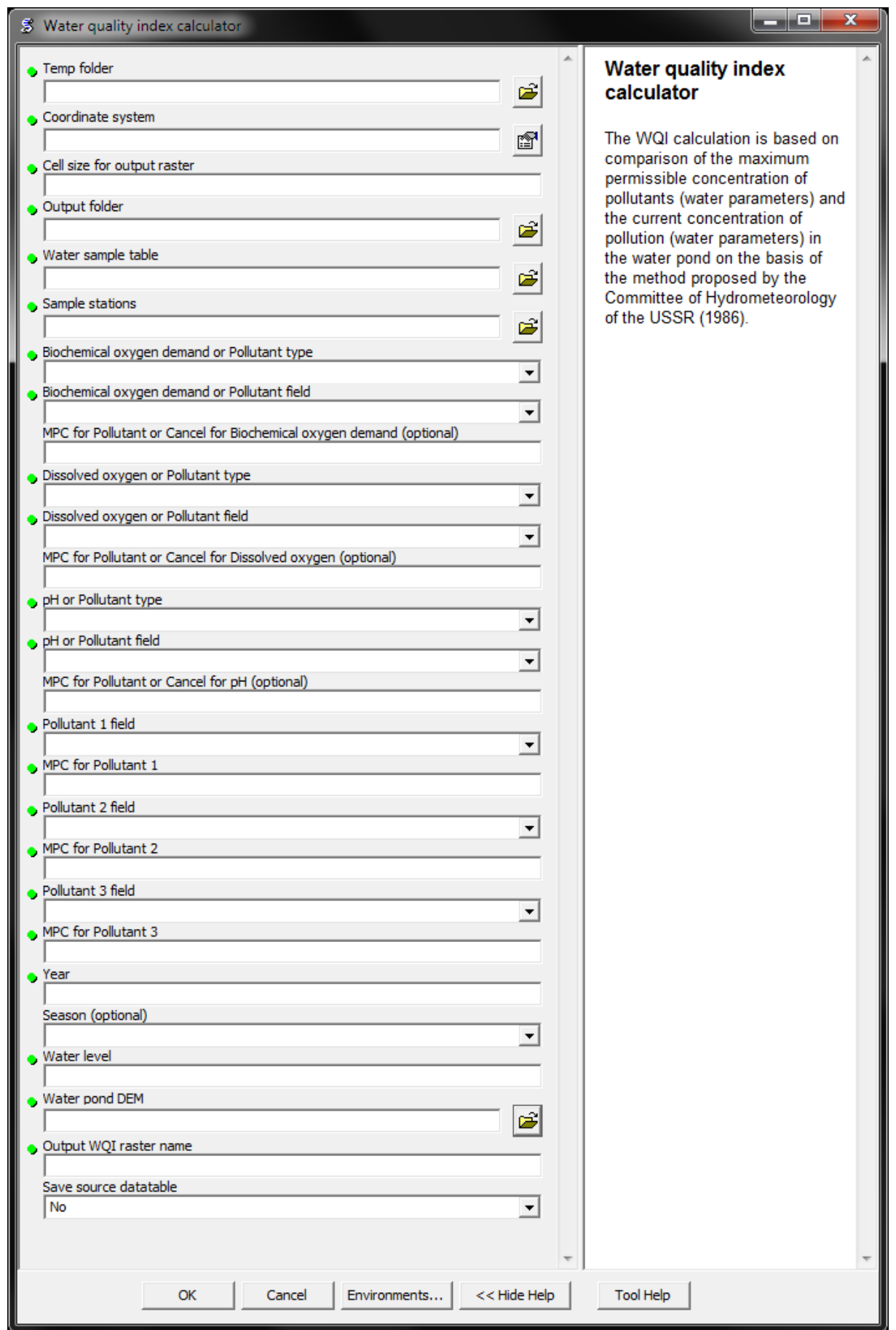

Figure 3-3: GUI window for the water quality index tool

The result of tool work was a raster that represents water quality spatial distribution. The combination with symbology reference ArcGIS layer brings high flexibility in the use of obtained data. It is possible to use the map with any kind of background map data supported by ArcGIS. 


\subsubsection{System architecture}

The client's research personnel (users) are highly qualified and well educated for work with complex data analysis and GIS software in the environmental field. The WQI mapping tool was developed for research purposes for individual desktop operation, giving the user access to change data.

All necessary GIS data processing and data format exchanges are handled by ArcGIS software.

The WQI mapping toolbox contains Python script for the following three basic sub processes: the calculation of shoreline of current water level, WQI calculation, and data interpolation. The elements of the system are described below:

- WQI calculation subtool calculates WQI data for the water sampling stations.

- Water samples results table is the data of laboratory water samples results. The data include: date of water sampling, name of the water sampling station and list of measured pollutants with its concentration.

- Water sample station disposition includes a layer with the disposition of the water sampling stations with attribute data including: name of the water sampling station, type of the water sampling station (inside or outside of the water body) and affiliation to the zone of the water body.

- The Shoreline calculation subtool creates Shoreline based on the current value of the water level. DEM element uses data of the depth of the water body.

- Current water level data regarding the water level of the water body.

- WQI interpolation subtool is used for the WQI interpolation. It generates data of the distribution of WQI through the water pond's area (WQI raster).

Figure 3.4 demonstrates the relationships between hardware, software, processes, data, and user sections. 


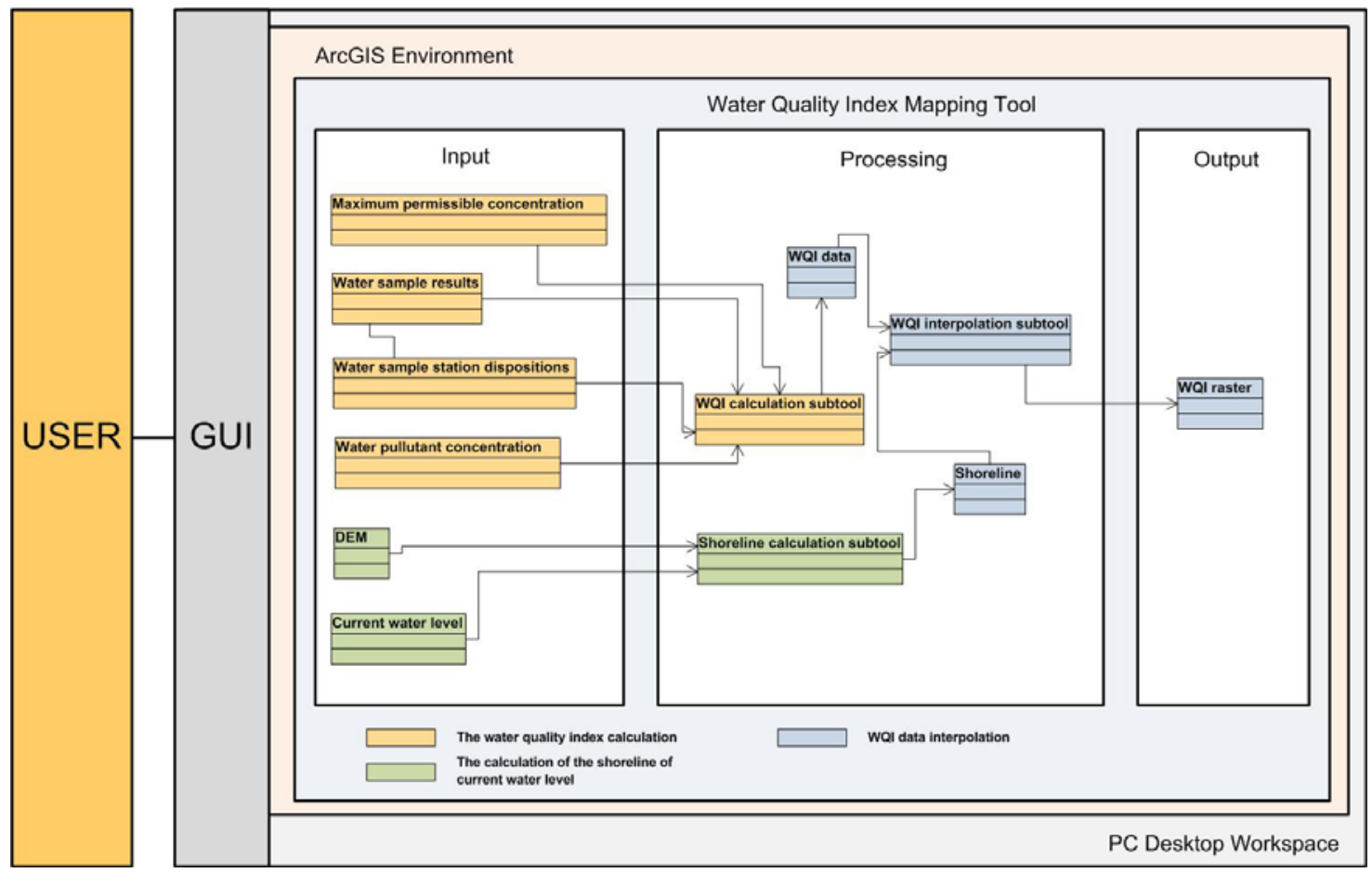

Figure 3-4: The workflow

\subsection{Project Plan}

\subsubsection{Challenges}

From the start of the project evaluation there were not any significant changes of project theme. From beginning to end the schema of project implementation just became more detailed and ways of implementation became clarified.

Only one point of the project was implementation changed, but only because of functionality limitations of ArcGIS geoprocessor 9.3.1 for Python. It was a transfer of a symbology from a reference layer to the output WQI raster. In case of software upgrade in ArcGIS 10 this feature will be implemented.

The client was also interested in a Web resource of data processing and presentation. It was not a mandatory condition, but it was preferable to fulfill the project by representing both desktop and web tools.

\subsubsection{Budget}

There were several main cost items for project implementation (from high to low): software, training, and hardware; data and data processing; and cost of time for tool design and development.

The software, training and hardware costs were separated between the developer and the client. The client already had the necessary software environment (ArcGIS) and his hardware satisfied project implementation requirements.

The entrance trainings for the client personnel was organized as instructor-led workshops and the help documentation were the part of the project delivery. 
The data for the project was the client's property and was provided at no cost.

\subsubsection{Deliverables}

The delivery of the project consisted of: the WQI tool as a Python script for the ArcGIS Environment (as an ArcGIS Toolbox), a geodatabase with the project data scheme, the technical documentation of the tool and an instructor-led workshop for the client personnel. The media for the data delivery was CD/DVD.

\subsubsection{Risks}

The riskiest aspects of the current project were: the bathymetry data, the data processing, the project management issue, and the issue of the client's business process changes.

The bathymetry data were old and mostly paper based; the data processing required several steps of preparation: careful digitizing of the data, data georeferencing, and data processing using different methods of interpolation, etc. All these steps, including the general low accuracy of the old paper data, reduced the accuracy of the whole project.

As the current project was small-scale with a limited scope for the management issue, the response for the problem was a close collaboration and step-by-step workflow discussion with executive personnel from the client's side.

There was an issue of the business process change, including the problem of customization and the minor changes in the business process within the client's organization. There were two solutions as a response plan: the detailed help documentation of the tool was prepared as part of the project delivery, and the description of the changes in the business process were taught during the instructor-led workshop.

\subsection{Summary}

The client for this project was Shikhaleeva Galina, Head of the Environment Monitoring Department, affiliated with the Institute of Physics and Chemistry for Environment and Human Protection. The client was responsible for monitoring environmental conditions of Kuyalnik Liman and needed GIS support to automate the water quality index (WQI) calculation process and to map the WQI spatial distribution. The calculation of the WQI was based on the exceeding of the maximum permitted concentrations of the pollutants.

The water quality index (WQI) mapping tool was developed as a desktop utility for a research staff workplace. It works under ArcGIS environment on PC platform computers.

The tool delivery included the tool with help documentation, operation manuals, and instructor-led workshop. The informational support was provided in case of mapping tool malfunction.

The riskiest aspects of the current project were: the data and data processing, the project management issue and the issue, of business process change. The migration from the old to the new workflow in the client's organization will be fully supported by training for client's personnel. The methodology for the data processing is correct for any data with higher accuracy. 


\section{Chapter 4 - Database Design}

The concept of the database design used in this project was built on a database structure provided by the client. The main objective of the project's database was to support the client's activity in environmental monitoring of Kuyalnik Liman in terms of water quality assessment using the WQI tool.

For this purpose the database contains such main classes as: water parameters that are obtained from laboratory sample analyses; water monitoring (sampling) stations that are distributed through the area of water body and the bathymetry data of Kuyalnik Liman for marking changes of shoreline of the water body.

\subsection{Conceptual Database Design}

There were several classes in the database that served as a data resource for the WQI calculation, according the method establish by State Committee of Hydrometeorology of the USSR (1986) described below (Figure 4-1):

- water samples results - a table with data of laboratory analyses of samples, collected through water body area. This table provides pollutant concentrations and some additions water parameters.

- water sample station disposition - feature class of the water monitoring station location through the water body.

- DEM - digital elevation model (bathymetry data) of bottom of a water body. It serves for shoreline calculation.

- $\quad$ mpc (maximum permissible concentration) - optional table with data of maximum allowable content of pollutants for different types of water use.

- Points2Water - the class of relationship between two tables, based on unique names of water monitoring stations.

Several domains were used in the database to avoid a misspelling of entering data. Presented in the database coded values domains are the legal values of fields for several classes:

- Month - list of months in year

- Season - list of seasons in year

- Pointkind - coded values that point to affiliation of water sampling station to area of water body or to water network

- Zone - coded values that point to affiliation of water sampling stations to specific zone of water body or to water network

- Type of water use (type_wat_use) - coded values that set MPC on the basis of type of water use of water body

- Issued agency (iss_agency) - publisher of MPC 


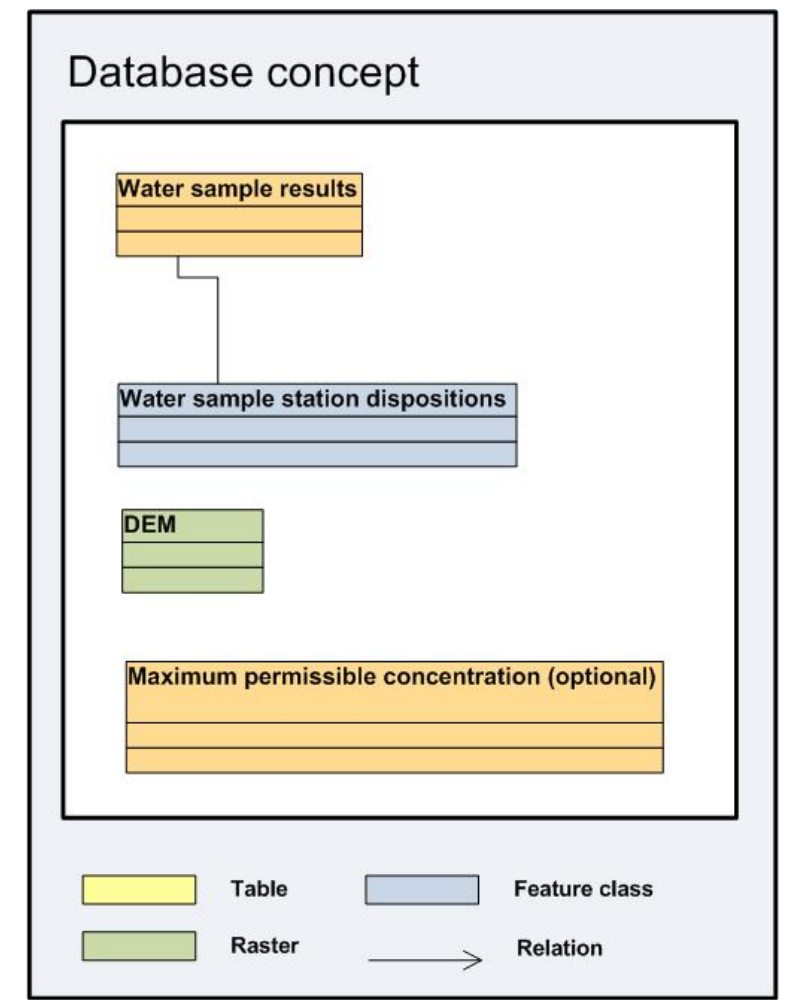

Figure 4-1: The database conceptual design.

\subsection{Database Implementation}

The implementation of the project database was made on the basis of ESRI File Geodatabase. This choice based on two reasons: the client's needs and necessity of project technology.

The client required a desktop solution for storing geographic and table data compatible with ESRI ArcGIS software. An ESRI File Geodatabase format was chosen as a fast, high performance solution for a single user or small group. This format also meets other project requirements such as: storing rasters in the geodatabase and improved locking schema (Childs, 2009).

There were several main segments in the project database: classes (tables and feature classes), domains, relationships, and the raster dataset. All spatial data were stored in a WGS 1984 UTM Zone 36N projection.

The classes consisted of two tables and one feature class:

- Table of water samples parameters. It contains results of laboratory analyses of water samples. The parameters from this table are used as input data for WQI assessment. The table has three domains: two temporal (month and season) and one that serves to point to monitoring station affiliation (pointkind) (Appendix A, Table A-1).

- Table of maximum permissible concentrations (MPC) for water resource; it also contains two service fields that help filter MPC by type of water use and by publisher (values for these fields are stored in domains). The MPC values serve as limit parameters for WQI calculations (Appendix A, Table A-2). 
- Feature class of water monitoring stations, Figure 2-3 in Chapter 2. Serves for calculation of spatial distribution of water parameters, also has two domains: one that serves to point to monitoring station affiliation (pointkind) and a second which serves for zone of water body marking (zone) (Appendix A, Table A-3).

Domains in the project geodatabase table were represented by coded value domain type. They are listed in Appendix A, Table A-4.

The semantic connection between the water samples parameters class and water monitoring stations class in the geodatabase was represented by relationship class Points2Water. It managed the associations between data affiliation to monitoring stations in one class and the monitoring stations dispositions in another. The description of the relationship class Points2Water is given in Appendix A, Table A-5.

The raster that represented the bathymetry of Kuyalnik Liman - DEM - was stored in the geodatabase as an ESRI Grid Raster Dataset. The measurement unit of this class was the meter in Baltic Elevation System (BES). Table A-6 from Appendix A illustrates this specification.

\subsection{Data Sources and Data Collection Methods}

The data used for the project implementation were provided by the client. However, it is necessary to give an idea of the data source that is served as a part of the project.

The water samples parameters table contained results of water sample analyses. The methods of these analyses and their precision varied, depended on the parameter and did not set in the database. The number and list of research parameters and methods are part of the accreditation of the laboratory and may change from one accreditation to another.

The water monitoring stations feature class located the disposition of water sampling stations. The disposition data were collected by handheld Garmin GPS12 and Garmin GPSMAP60 during the field work.

The bathymetry data of Kuyalnik Liman was based on data of a field survey that was conducted by the Ukrainian Research Institution of Balneology in 1975. The four paper maps from the report of UkrRIbalneology (1975) represented the network of depth measurements of Kuyalnik Liman. The maps contained the point data with elevation marked in BES and three isolines of depth in BES of the Kuyalnik Liman. For example, Figure 4-2 shows map of the northern part of Kuyalnik Liman. 


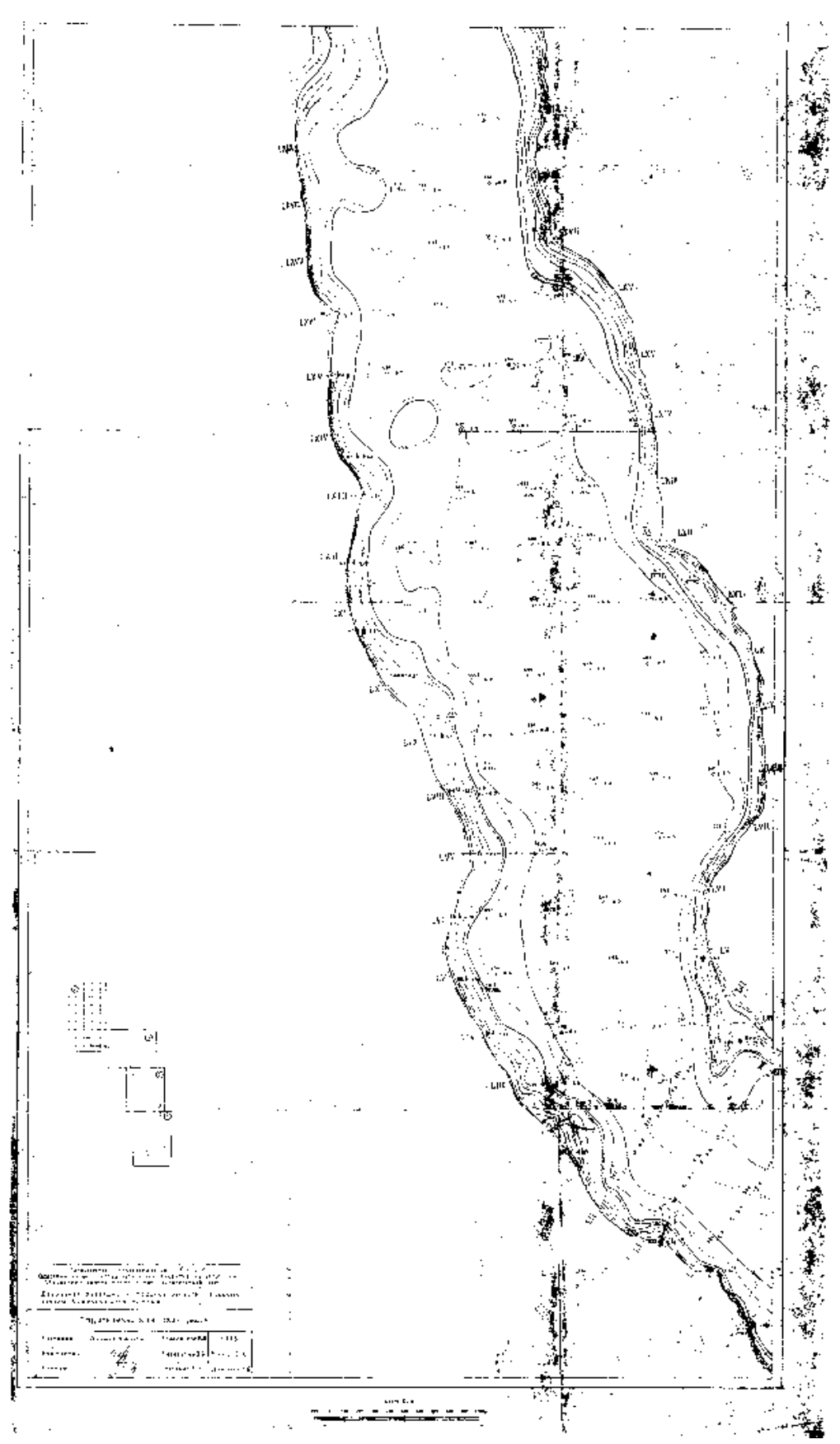

Figure 4-2: The hardcopy of Kuyalnik Liman bathymetry, northern part.

\subsection{Data Scrubbing and Loading}

There were two main reasons for data scrubbing and loading the data: the preparation of the water samples table and creation of the bathymetry data of Kuyalnik Liman.

The water sample data were processed and prepared for the SQL statements. The code for absence of laboratory analyze (the analysis were not made) was marked as 0 , the analyze that were made but obtained results were below detection levels were marked as 
0.0000000001 . These changes allowed the user to query the analysis data for meaningful results with the statement $[>0]$.

There were several steps for the bathymetry data processing. The scanned paper maps were georeferenced in WGS 1984 UTM Zone $36 \mathrm{~N}$ projection on the basis of the Landsat remote satellite imagery. From the digitizing of the georeferenced maps were obtained: feature class of points with depth values in Baltic Elevation System (BES) and feature class of isolines of depth of Kuyalnik Liman with marks: -4.7, -5.0 and -6.0 meters in BES (Figure 4-3).

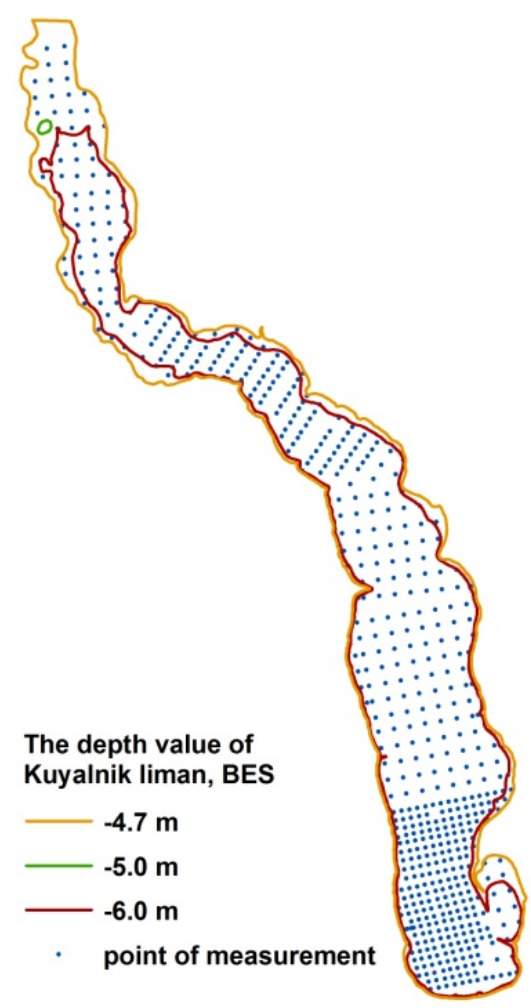

Figure 4-3: The data for the bathymetry data processing.

Topo to Raster was chosen as the method for the bathymetry data raster creation from the ESRI Spatial Analyst toolbox as a method that provides hydrographically correct relief (ESRI, 2010).

\subsection{Summary}

The design for the project database was inherited from the database structure provided by the client. The database contained the classes: water parameters that are obtained from laboratory sample analyses; water monitoring stations that are distributed through the area of a water body, and bathymetry data of Kuyalnik Liman for marking the changes of shoreline. 
Several domains were used in the database. Presented coded values domains were the legal values of fields for several classes: Month - list of months in year, Season - list of seasons in year; Pointkind - coded values that point to affiliation of water sampling stations to area of water body or to water network; Zone - coded values that point to affiliation of water sampling stations to a specific zone of water body or to water network; Type of water use - coded values that mark MPC on the basis of type of water use of water body and Issued agency - publisher of MPC. All spatial data are stored in a WGS 1984 UTM Zone 36N projection.

The semantic connection between water samples parameters class and water monitoring stations class in the geodatabase was represented by relationship class Points2Water.

The data used for the project implementation were provided by the client. The data of disposition of water monitoring stations were collected by handheld Garmin GPS12 and Garmin GPSMAP60 during the field work. The bathymetry data of Kuyalnik Liman were based on paper maps from a field survey that was conducted by Ukrainian Research Institution of Balneology in 1975. Topo to Raster tool was chosen as a method for the bathymetry data creation that provides hydrographically correct relief. 


\section{Chapter 5 - Implementation}

As mentioned in previous chapters, the implementation of the project was based on the methodology of a water quality index (WQI) calculation proposed by State Committee of Hydrometeorology of the USSR (1986) within a Python and ArcGIS geoprocessing framework.

The first part of this chapter describes the method of the WQI calculation; the second part details Python code implementation and using of ArcGIS geoprocess tools.

\subsection{The Method of WQI calculation}

The WQI used for this project is the hydro-chemical index of water pollution proposed by State Committee of Hydrometeorology of the USSR (1986). It is widely used throughout the territory of the former Soviet Union countries as the method for assessment of water quality for water ponds; the copy of methodology in original (Russian) language is given in Appendix C.

This index is typical additive coefficient and represents average contribution of maximum permissible concentrations (MPC) exceeding on the basis of limited water ingredients (water parameters and pollutants).

The formula for the WQI calculation is:

Where:

$$
\mathrm{WQI}=\frac{1}{\mathrm{n}} \sum_{\mathrm{i}=1}^{\mathrm{n}} \frac{\mathrm{C}_{\mathrm{i}}}{\mathrm{MPC}_{\mathrm{i}}}
$$

- $\mathrm{C}_{\mathrm{i}}=$ concentration (value) of water ingredient (water parameters and (or) pollutants)

- $\mathrm{n}=$ number of water ingredients (water parameters and (or) pollutants)

- $\mathrm{MPC}_{\mathrm{i}}=$ maximum permissible concentration for this type of water use

The WQI calculates for different numbers of water parameters and pollutants, including $\mathrm{pH}$ value, biochemical oxygen demand and dissolved oxygen. For this it is necessary to calculate the ratio $\mathrm{C}_{\mathrm{i}} / \mathrm{MPC}_{\mathrm{i}}$. The WQI is calculated on the basis of six parameters.

There are several rules for the WQI calculation for some standardized water parameters:

- There are special norms for a biochemical oxygen demand that depends on current the value of the parameter, Figure 5-1. 


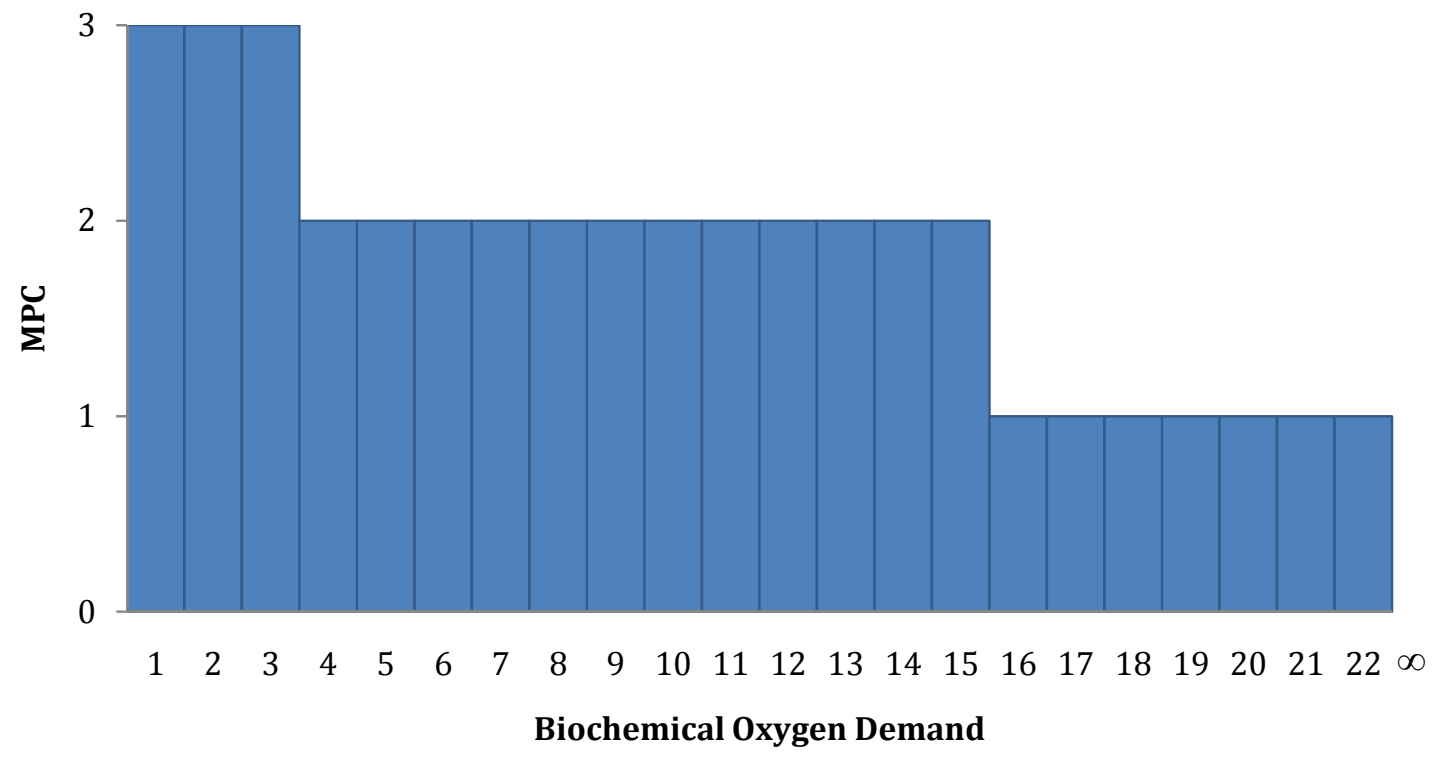

Figure 5-1: MPC relationship to biochemical oxygen demand level.

- There are ratio $C_{i} / M P C_{i}$ values that depend on dissolved oxygen value, Figure 5-2.

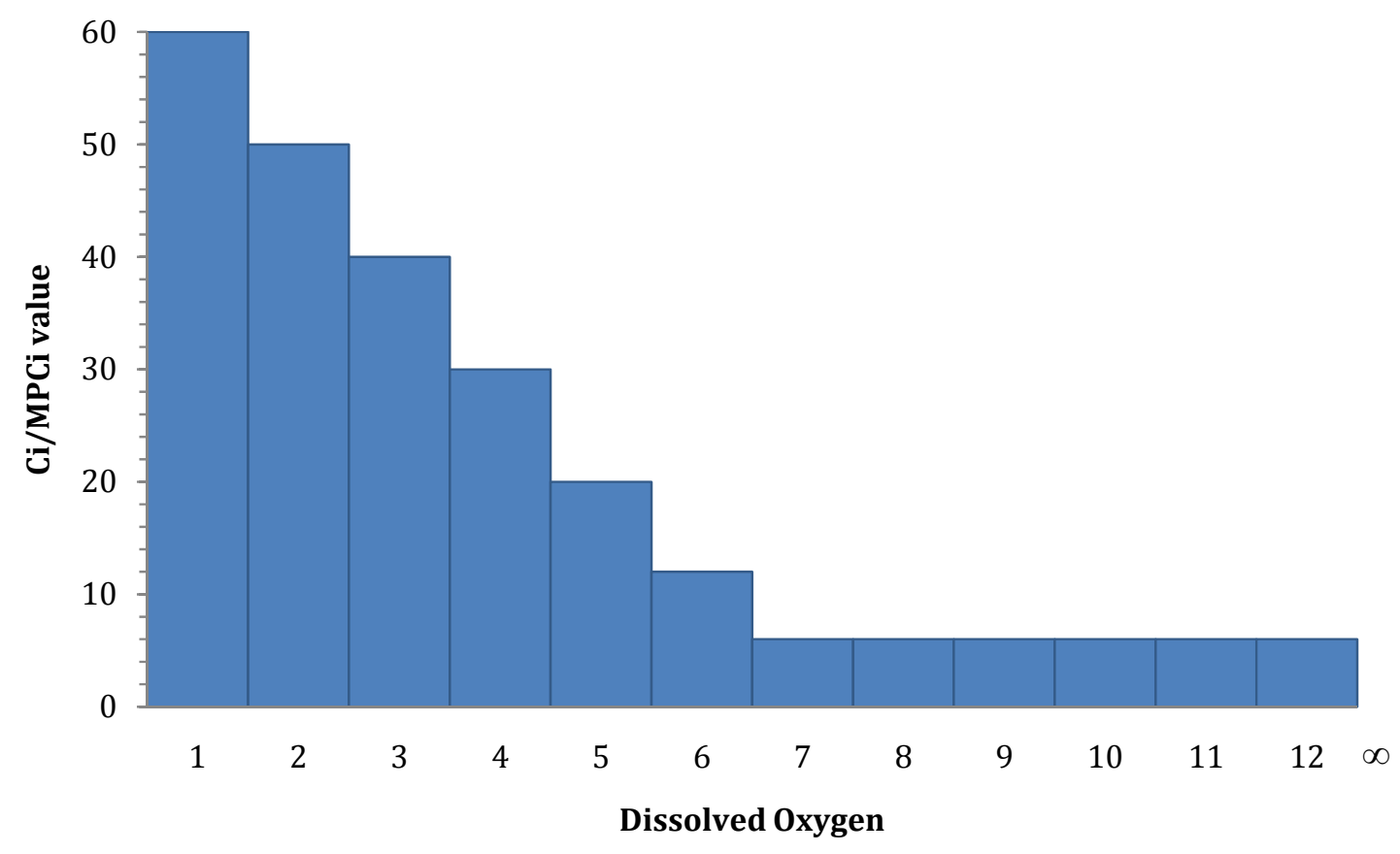

Figure 5-2: $C_{i} / M C_{i}$ relationship to dissolved oxygen level.

- There is a limit of 6.5 to 8.5 for a $\mathrm{pH}$ values for water ponds. So the ratio $C_{i} / M P C_{i}$ values depend on exceeding of this limit, Figure 5-3. 


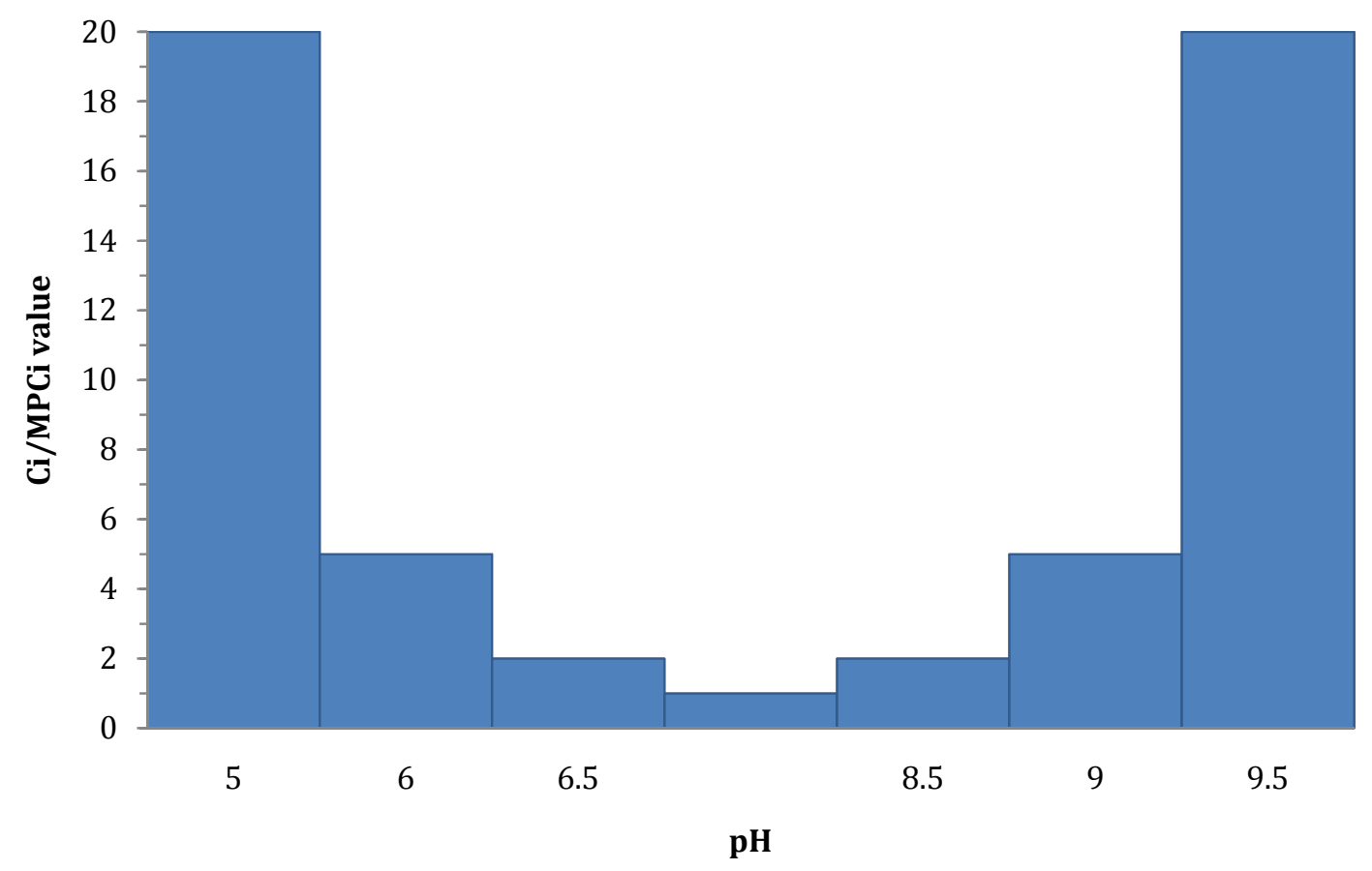

Figure 5-3: $\mathrm{C}_{\mathrm{i}} / \mathrm{MPC}_{\mathrm{i}}$ relationship to $\mathrm{pH}$ level.

There is a class division on the basis on the calculated WQI value:

Table 1. The water quality classes.

\begin{tabular}{|l|l|l|}
\hline Water purity & WQI value & Water quality class \\
\hline Very clean & less than 0.2 & I \\
\hline Clean & $0.2-1.0$ & II \\
\hline Moderately impure & $1.0-2.0$ & III \\
\hline Impure & $2.0-4.0$ & IV \\
\hline Polluted & $4.0-6.0$ & V \\
\hline Very polluted & $6.0-10.0$ & VI \\
\hline Extremely polluted & more than 10.0 & VII \\
\hline
\end{tabular}


There is a requirement that the WQI be compared only for water body of same biogeochemical province and similar type; for the same water body or waterway and with a consideration of water content of current year. In case of this project these requirements were met.

\subsection{Workflow of the WQI calculation}

Below is the description of use of ArcGIS geoprocessing tools and variables through the algorithm of the WQI calculation. The detailed Python code listing is provided. The algorithm is described in Figure 5-4 by main functions. The full listing of Python code is provided in Appendix B. Figure 3.3 in Chapter 3 shows the full view of the tool's GUI in ArcGIS environment.

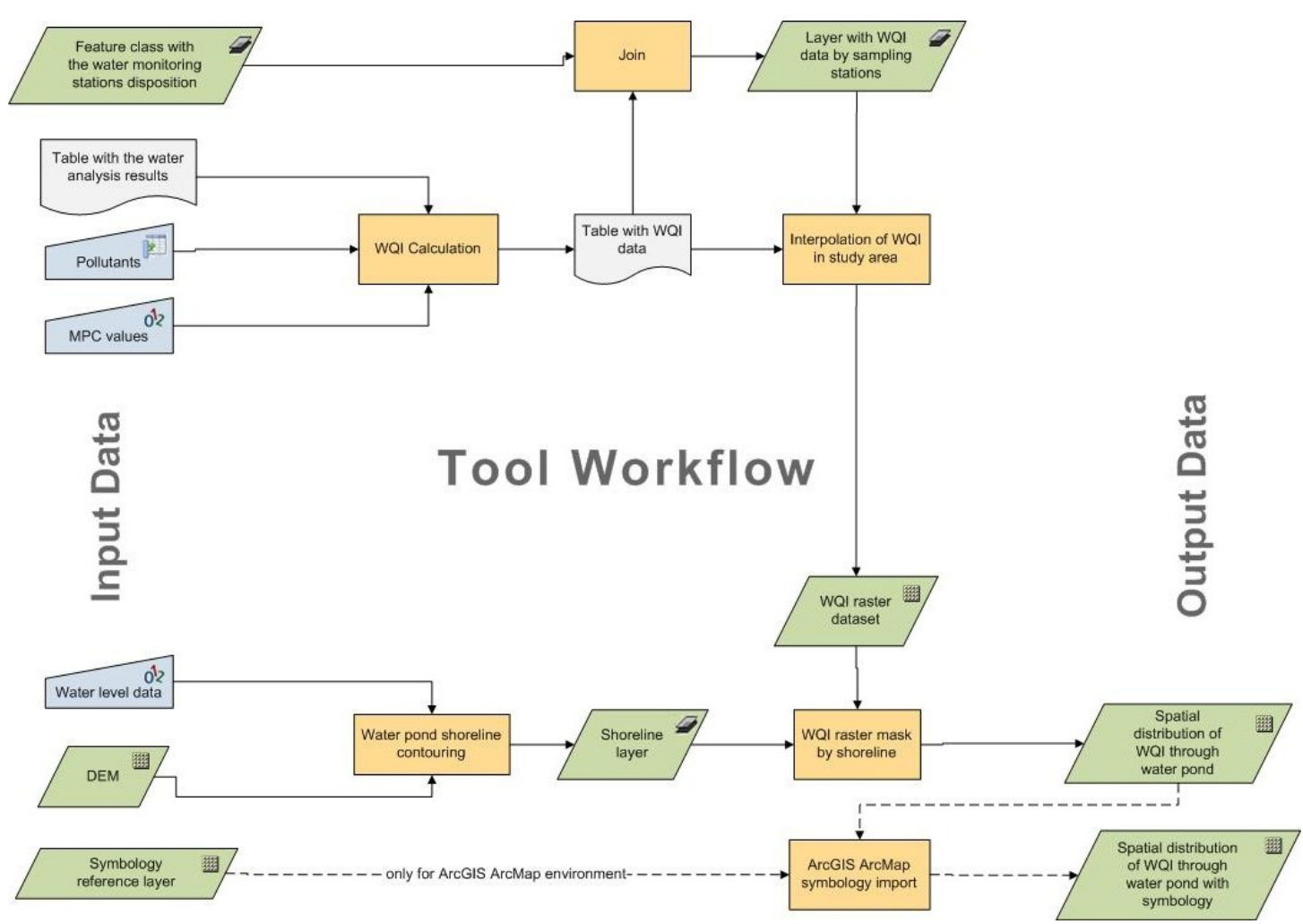

Figure 5-4: The algorithm of the WQI tool by main functions.

There were several required service variables that help correct ArcGIS geoprocess tools running (the input view is shown at Figure 5-5):

- Temp folder variable - the temporary folder for data that are created during the tool running. The ArcGIS GUI data type of Temp folder variable is Folder.

- Coordinate system variable - the coordinate system for a study area. To avoid potential errors it is highly recommended to reproject all input data to one coordinate system before tool use. The ArcGIS GUI data type of Coordinate system variable is Coordinate system. 
- Cell size for output raster - the cell size for result water quality index raster in the previously input coordinate system units. The ArcGIS GUI data type of Cell size for output raster variable is Long (long integer).

- Output folder - the folder for the output water quality index raster. The ArcGIS GUI data type of Output folder variable is Folder.

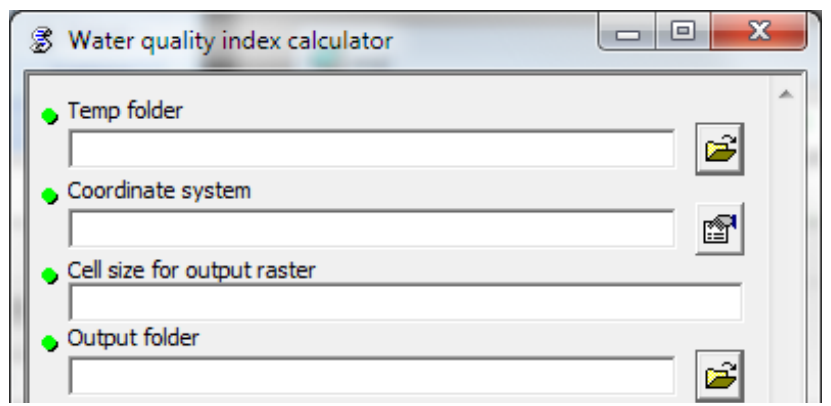

Figure 5-5: The service variable input tool GUI.

The Python code for input of these variables:

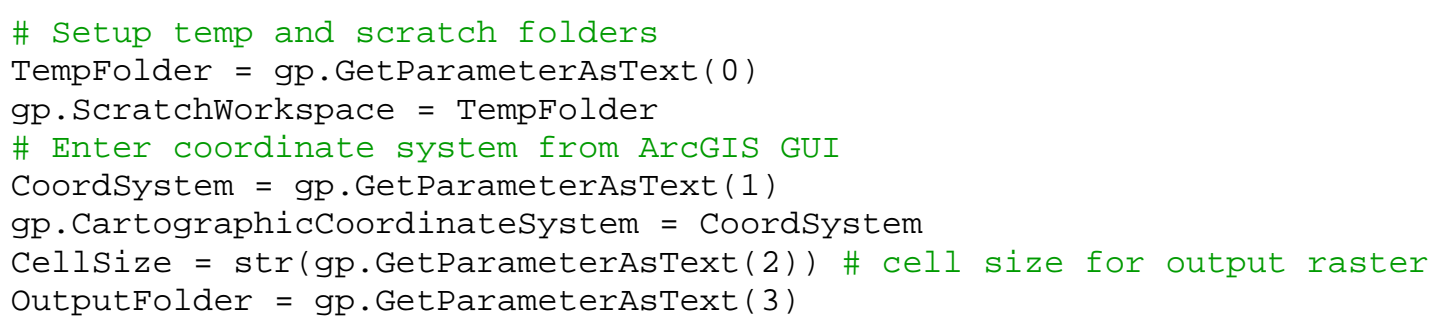

The main input data for the WQI calculation was represented by several mandatory datasets.

Water sample table was the input tabled data of laboratory water samples results (list of measured pollutants with their concentration). The mandatory service fields for this table for the WQI calculation were: year for sampling year, season for sampling season, pointkind for a sample affiliation: to water area of water body (a) or to water network (w), n_point as a name of the water sampling station.

Sample stations was the feature layer with the disposition of the water sampling stations with their attribute data. The mandatory service field of this feature class for the WQI calculation was $n \_$point as a name of the water sampling station.

For the WQI calculation it was necessary to take six water pollutants and/or water parameters. The inputs of the first three pollutants were combined with the ability to choose one of three water parameters that might be taken into account in the WQI calculation: biochemical oxygen demand, dissolved oxygen, and $\mathrm{pH}$. So there were several service fields for choosing type of input value: regular pollutant or one from three water parameters. The input has the choice of biochemical oxygen demand, dissolved oxygen, and $\mathrm{pH}$. In case for choosing any of water parameter instead pollutant the "MPC for Pollutant ..." fields should be left blank. Otherwise the MPC value should be entered for each pollutant.

The input view for the main input data is shown in Figure 5-6 


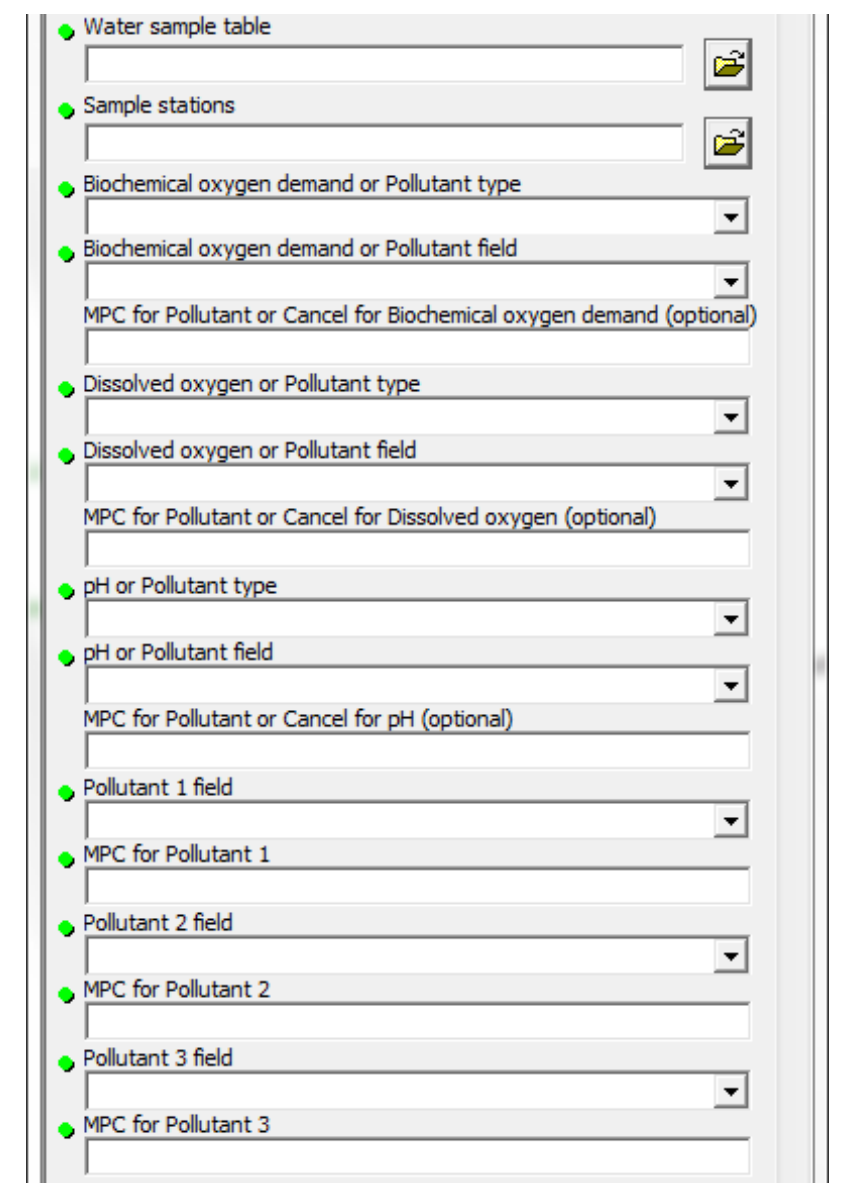

Figure 5-6: The main data input tool GUI.

The Python code for main input data:

\# Input table with water parameters

WaterSampleTable = gp. GetParameterAsText (4)

\# Input feature class of water monitoring stations

WaterSampleStations = gp.GetParameterAsText(5)

\# Entering water parameters fields

WaterParameterType4BPK = gp.GetParameterAsText (6)

WaterParameterBPK = gp.GetParameterAsText (7)

WaterParameterMPC4BPK = gp.GetParameterAsText (8)

WaterParameterType40 = gp.GetParameterAsText (9)

WaterParameter0 = gp. GetParameterAsText (10)

WaterParameterMPC40 = gp.GetParameterAsText (11)

WaterParameterType4Ph = gp.GetParameterAsText(12)

WaterParameterPh = gp. GetParameterAsText (13)

WaterParameterMPC4Ph = gp.GetParameterAsText (14)

WaterParameter1 = gp.GetParameterAsText (15)

WaterParameterMPC1 = gp. GetParameterAsText (16)

WaterParameter 2 = gp. GetParameterAsText (17)

WaterParameterMPC2 = gp. GetParameterAsText (18)

WaterParameter $3=$ gp. GetParameterAsText (19)

WaterParameterMPC3 = gp.GetParameterAsText (20) 
The Year and Season parameters confined data for the WQI calculation. The WQI might be calculated for any of four chosen seasons or for a whole year. In the last case the field Season should be left blank. There was a formula for a winter season; the WQI of a winter season was calculated on the basis of January and February of the current year and December of the previous year. The input view for the described parameters is shown in Figure 5-7.

\section{Figure 5-7: The year and season input tool GUI.}

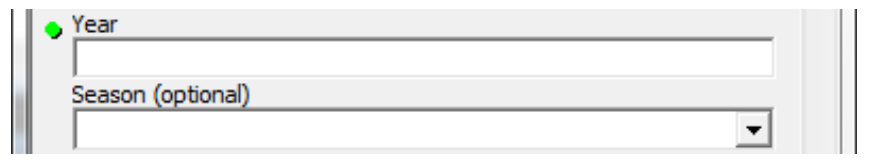

The Python code listing for these parameters:

Year = gp. GetParameterAsText(21) \# query year

PreviousYear = int (Year) - 1 \# additional query year for winter query Season = gp. GetParameterAsText(22) \# query season

There were two inputs for the shoreline calculation:

- Water level - the value of level of water for a query time period.

- Water pond DEM - the path to the dataset of digital elevation model of water body

And the input for the name of output water quality index raster. The input view for these last three input parameters is shown in Figure 5-8.

Figure 5-8: The shoreline calculation and output raster tool GUI.

The Python code listing for these input parameters:

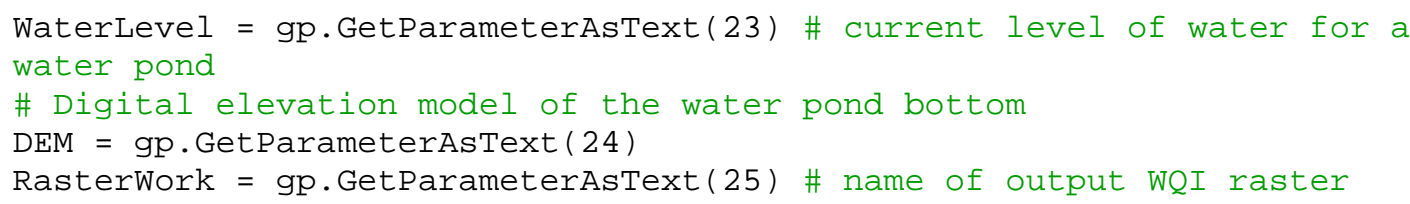

It was necessary for the WQI calculation that the all values of the water parameters and/or water pollutants were more than zero. The temporal query table was created for this purpose by the MakeQueryTable geoprocess function.

There were several preprocess steps in Python code for the implementation:

- Generation of list of fields:

\# List of water parameters 
WaterParameter = WaterParameterBPK + "; " + waterParametero + "; " + WaterParameterPh + "; " + WaterParameter1 + "; " waterParameter2 + "; " + WaterParameter 3 + "; "

\# Common field list for query table

FieldsList $=$ WaterParameter + WaterSampleTableNameField

- The season query:

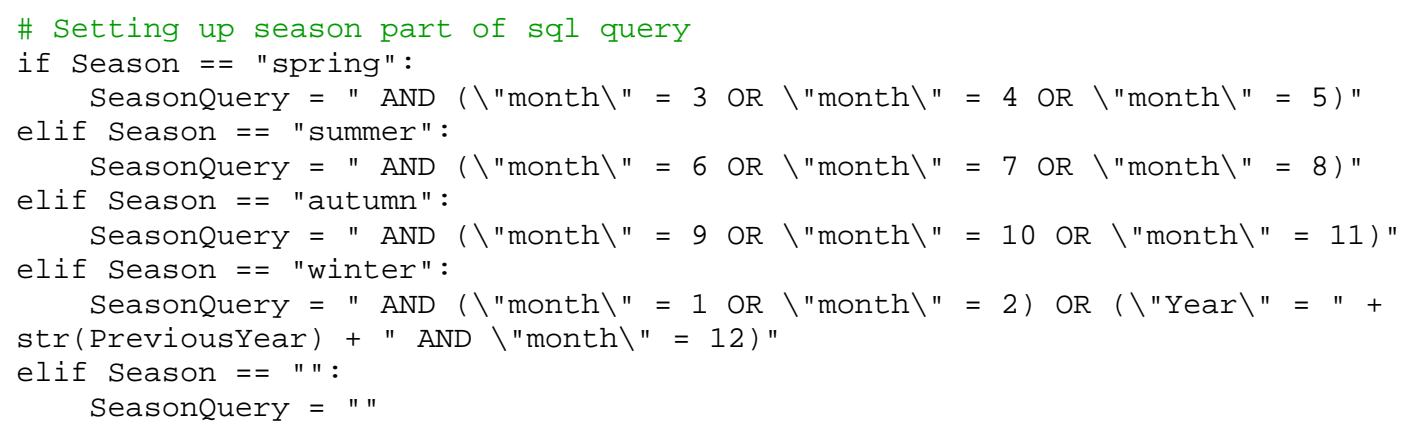

- The water parameter query:

\# Setting up water parameter for sql query

WaterParameterQuery = waterParameterBPK + " > $\odot$ AND " + waterParameter0 $+">\odot$ AND " + waterParameterPh + " > $\odot$ AND " + waterParameter1 + " > $\odot$ AND " + waterParameter 2 + " > $\odot$ AND " + waterParameter 3 + " > $\odot$ AND "

- The whole query:

\# Whole sql query for a making query table SQLQuery = waterParameterQuery + "\"pointkind $\backslash "$ = 'a' AND \"Year $\backslash "$ = " $+\operatorname{str}($ Year $)+$ SeasonQuery

The temporal query table creation:

\# Make Query Table...

gp.MakeQueryTable(WaterSampleTable, "TempQueryTable", "ADD_VIRTUAL_KEY_FI ELD", " ", FieldsList, SQLQuery)

This part of the code checks absence of results data in the query table:

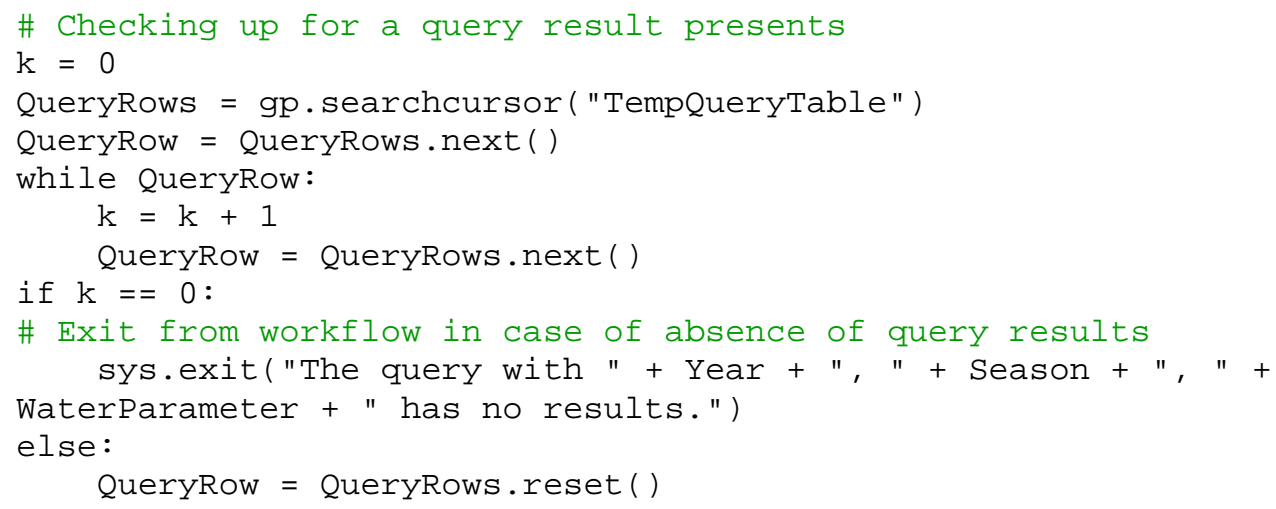


The selected rows potentially give the number of parameter values per water monitoring station. So, it is necessary to average the selected values for the query time period. For this purpose geoprocess Statistic tool and preprocess query were used:

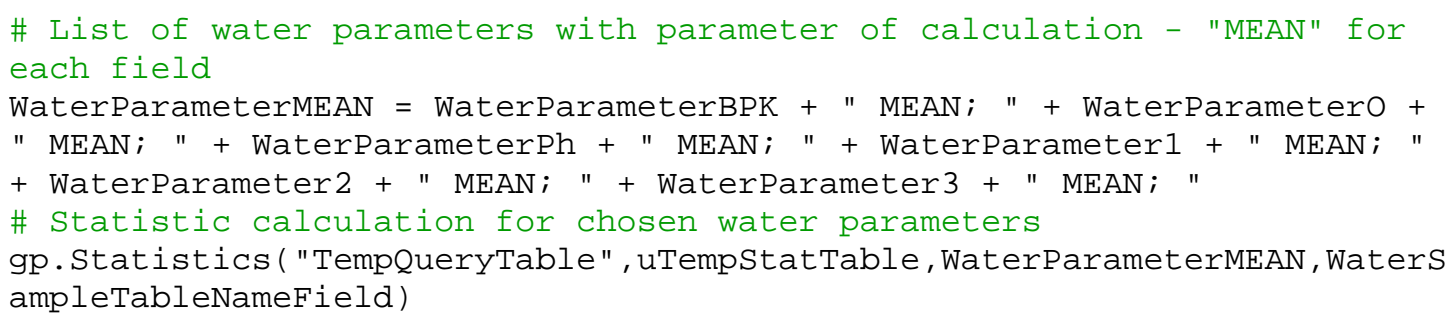

The implementation of the WQI formulas was based on CalculateField ArcGIS geoprocessing tool. There were several preprocess steps for this operation: adding field for WQI value to the existed temporal statistic table, preprocessing water parameters, and expression of WQI calculation:

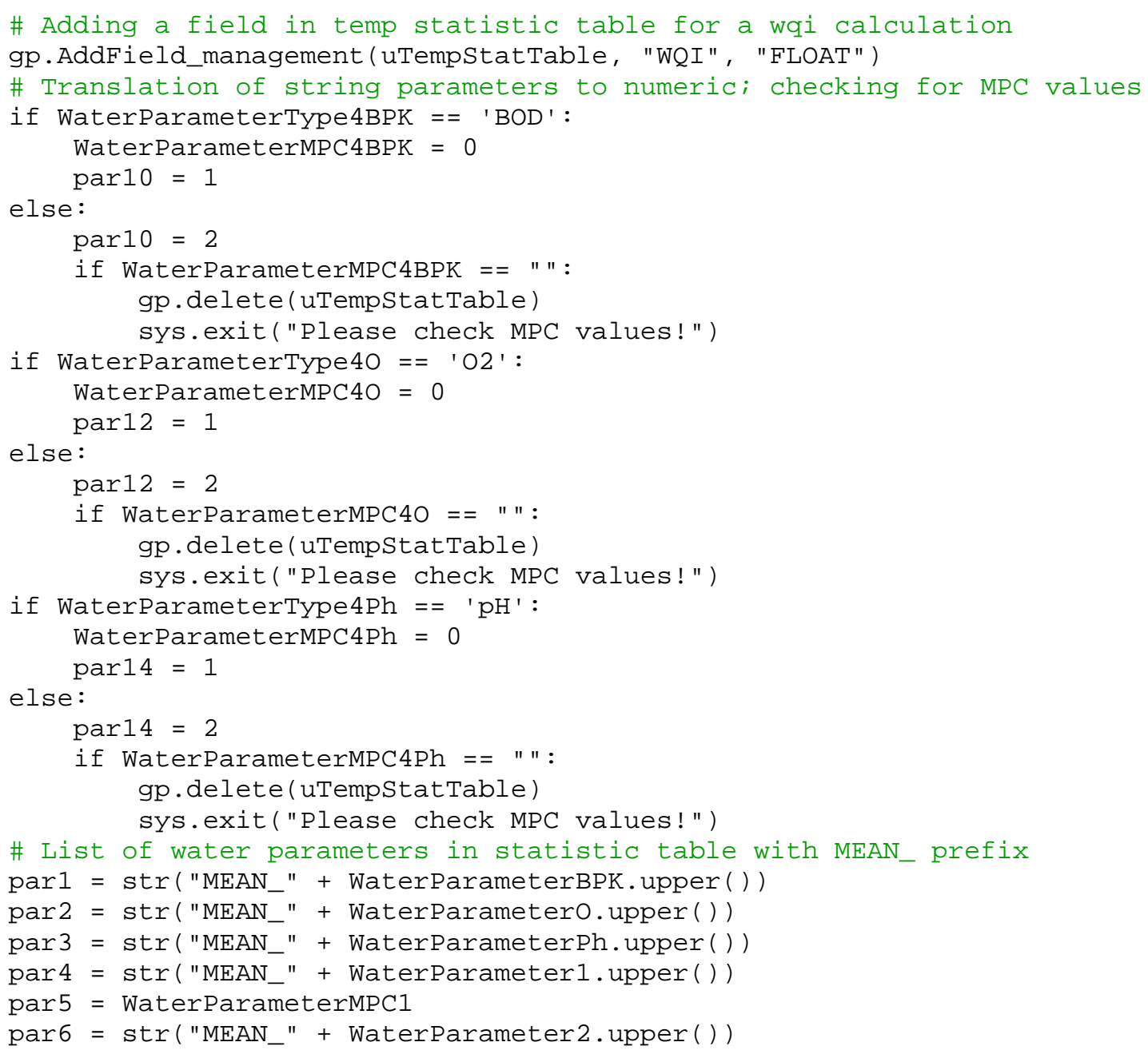


par7 = WaterParameterMPC2

par8 = str ("MEAN_" + WaterParameter $3 . \operatorname{upper}())$

par9 = WaterParameterMPC3

par11 = WaterParameterMPC4BPK

par13 = waterParameterMPC40

par15 = waterParameterMPC4Ph

\# Expression for field WQI calculation. Names of fields of water

parameters are limited by 16 symbols

ExpressionWQI =

"WQICalculation (\%s, \%s, \%s, \%s, \%s, \%s, \%s, \%s, \%s, \%s, \%s, \%s, \%s, \%s, \%s)" \% ( " " + par1 $[0: 16]+"$ !", "!" + par2[0:16]+"!", "!" + par3[0:16]+"!", "!" + par4[0:16]+"!", par5, "!" + par6[0:16]+"!", par7, "!" + par8[0:16]+"!", par9, par10, par11, par12, par13, par14, par15)

After preprocessing of the necessary variables for the WQI calculation the WQI formula was implemented as Python block inside the CalculateField function:

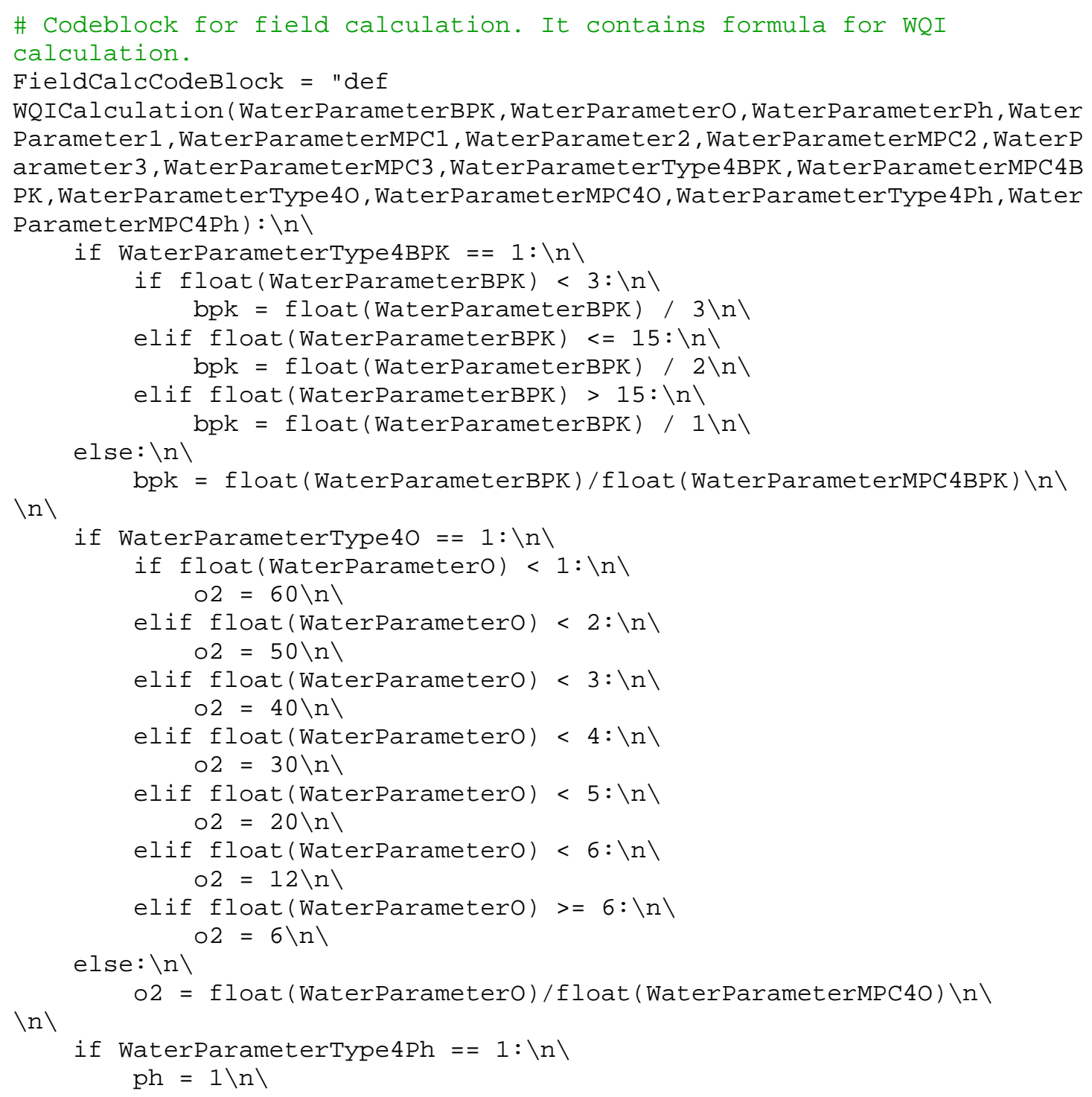




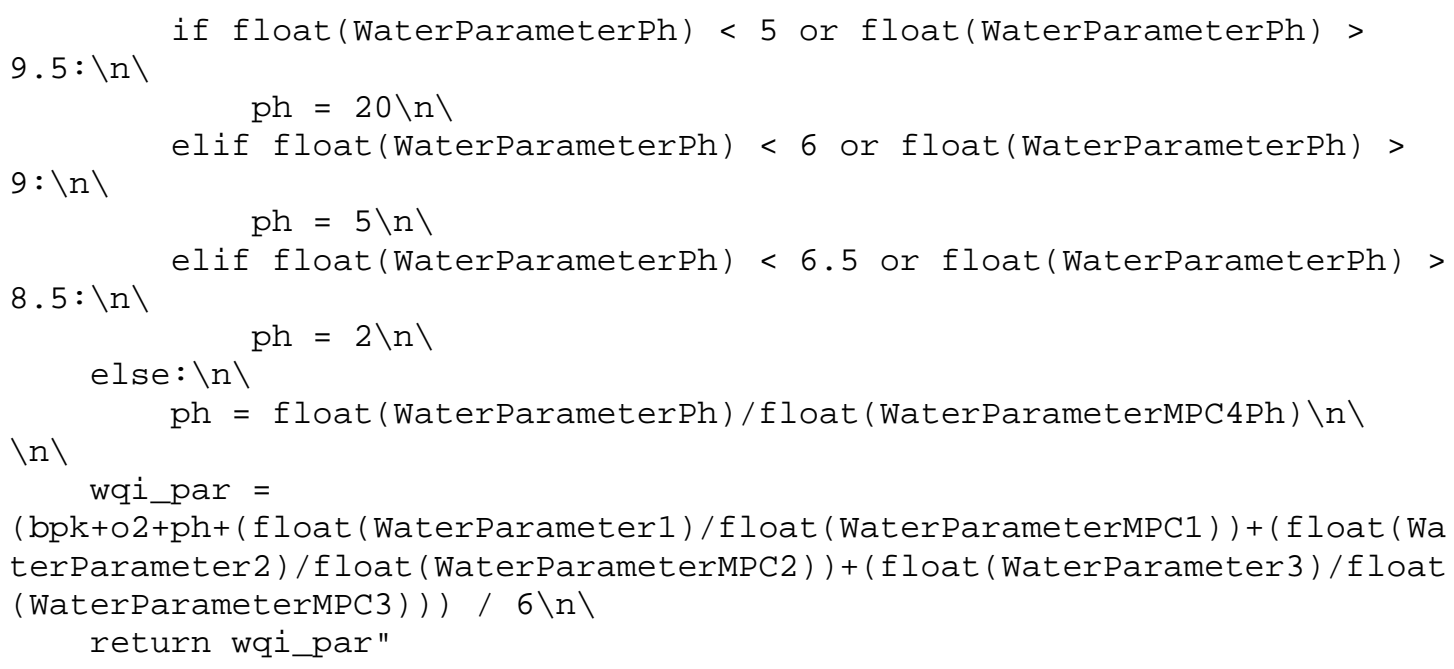

And the coding of CalculateField function:

gp.CalculateField_management(uTempStatTable, "WQI", ExpressionWQI, "PYTHON_9.3", FielddCalcCodeBlock)

The next main operation was a Join function, which combined data of the WQI calculation and feature class of water monitoring station disposition. For this purpose the temporal feature layer was made from the feature class of water monitoring station disposition:

\# Creation of temporal layer from the feature class of monitoring stations gp. MakeFeatureLayer (WaterSampleStations, "WaterSampleStationsTemp") \# Join feature class with sample station disposition and table with WQI calculated gp.AddJoin_management ("WaterSampleStationsTemp", WaterSampleTableNameField, uTempStatTable, waterSamplestationsNameField, "KEEP_COMMON")

Before the interpolation the WQI data it was necessary to set up the extent of the study area. In this case this extent depended on shoreline for the water level of the current query. So the shoreline processing was for two purposes: getting the coordinates for the interpolation extent, and preparing the polygon feature for the WQI raster mask. The Python code for these purposes is provided below:

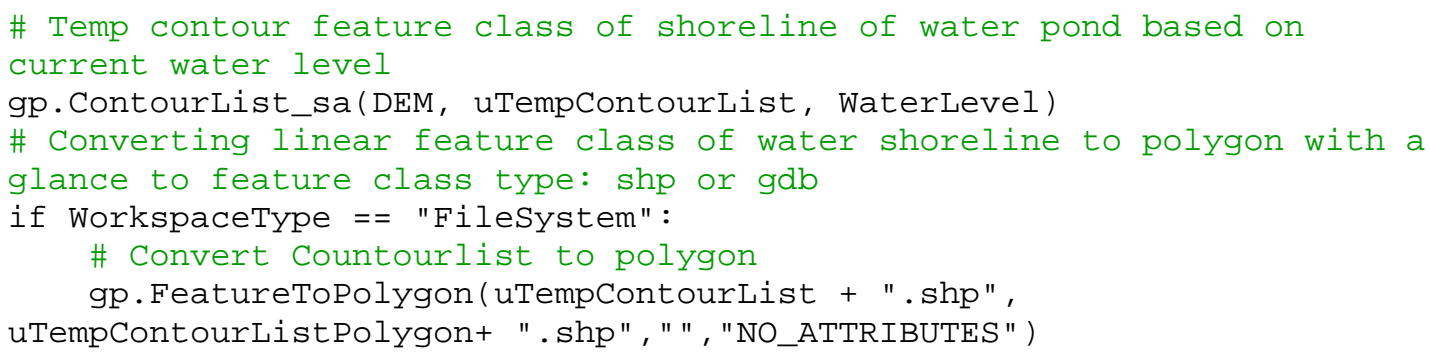




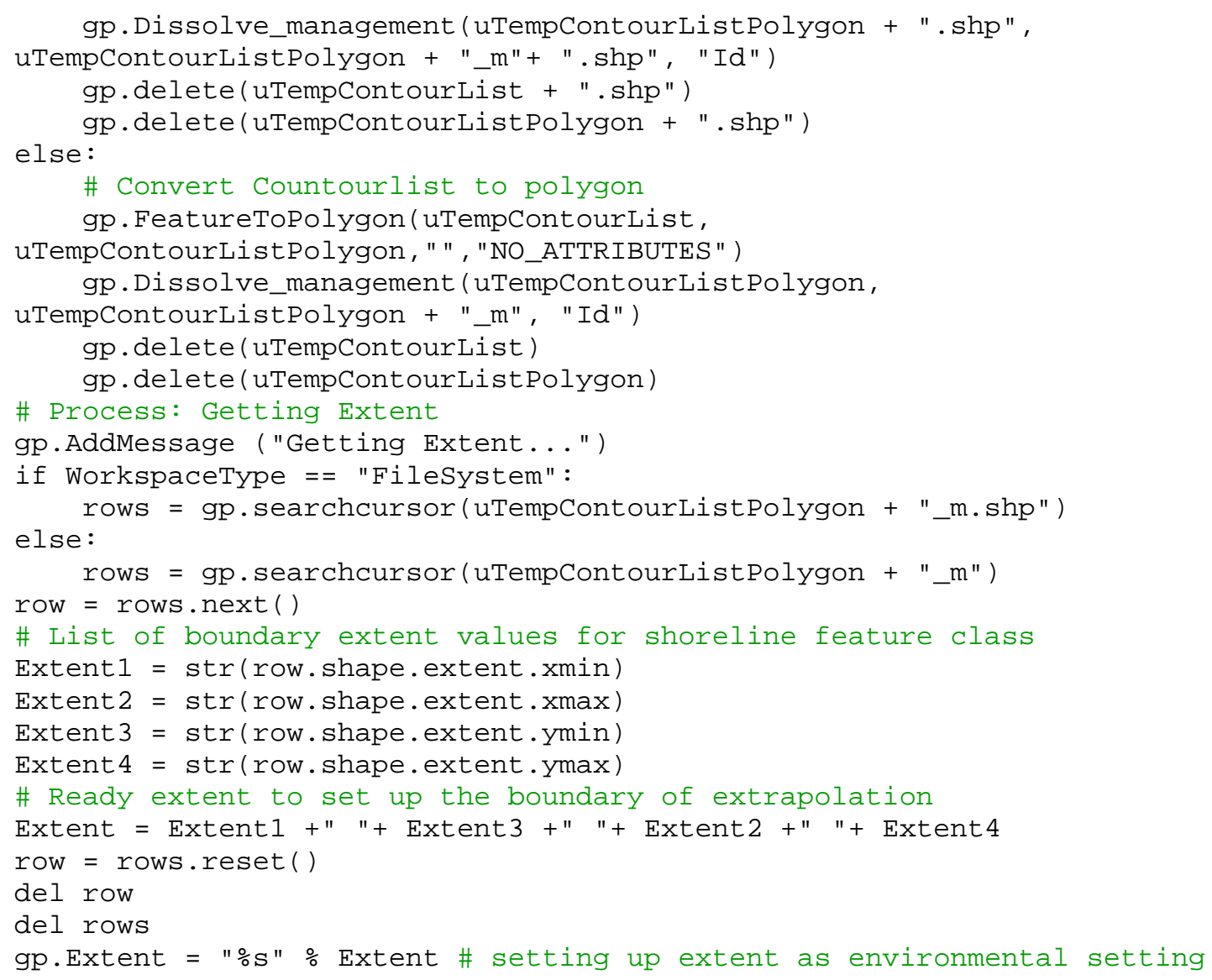

The interpolation of WQI values between water monitoring stations and inside the area of interest (the extent of the shoreline) was based on an inverse distance weighted (IDW) method.

According to Bolstad (2008), the IDW method estimates the value at unknown points using the sampled values and distance to nearby known points. The weight of each sample is an inverse proportion to the distance. The formula for the IDW calculation is:

Where:

$$
\mathrm{Z}_{\mathrm{j}}=\frac{\sum_{\mathrm{i}} \frac{\mathrm{Z}_{\mathrm{i}}}{\mathrm{d}_{\mathrm{ij}}^{\mathrm{n}}}}{\sum \mathrm{i}_{\mathrm{i}} \frac{1}{\mathrm{~d}_{\mathrm{ij}}^{\mathrm{n}}}}
$$

- $\mathrm{Z}_{\mathrm{j}}$ is the estimated value for the unknown point at location $\mathrm{j}$

- $\mathrm{d}_{\mathrm{ij}}^{\mathrm{n}}$ is the distance from known point $\mathrm{i}$ to unknown point $\mathrm{j}$

- $\mathrm{Z}_{\mathrm{i}}$ is the value for the known point $\mathrm{i}$

- $\mathrm{n}$ is a user-defined exponent

The use of this method of interpolation for the current project was proposed and endorsed by the client. Kuyalnik Liman is a shallow water pond without vertical water stratification, and without sharp differences in water parameters values through the liman area. So using of IDW method of interpolation for this project was proper. 
Raster, obtained after interpolation, represents the spatial distribution of WQI through the area of interest. Confining the area of the water body by the shoreline the geoprocess tool ExtractByMask was used. The Python code for these functions:

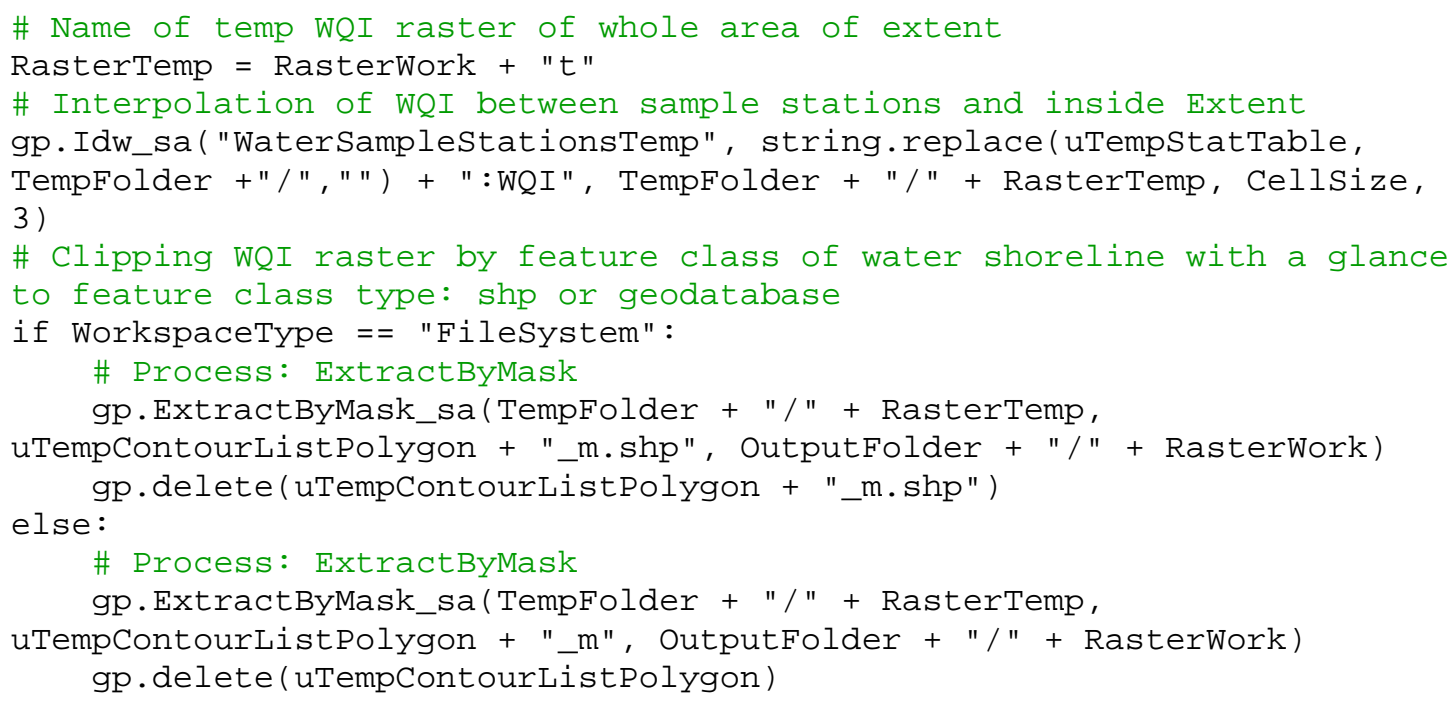

The symbology import function of the WQI tool is available only in the ArcGIS ArcMap environment. The symbology reference layer was chosen in the tool properties dialog window (Figure 5-9). The Python code for this:

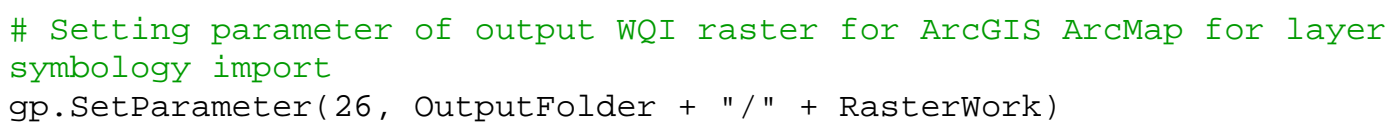




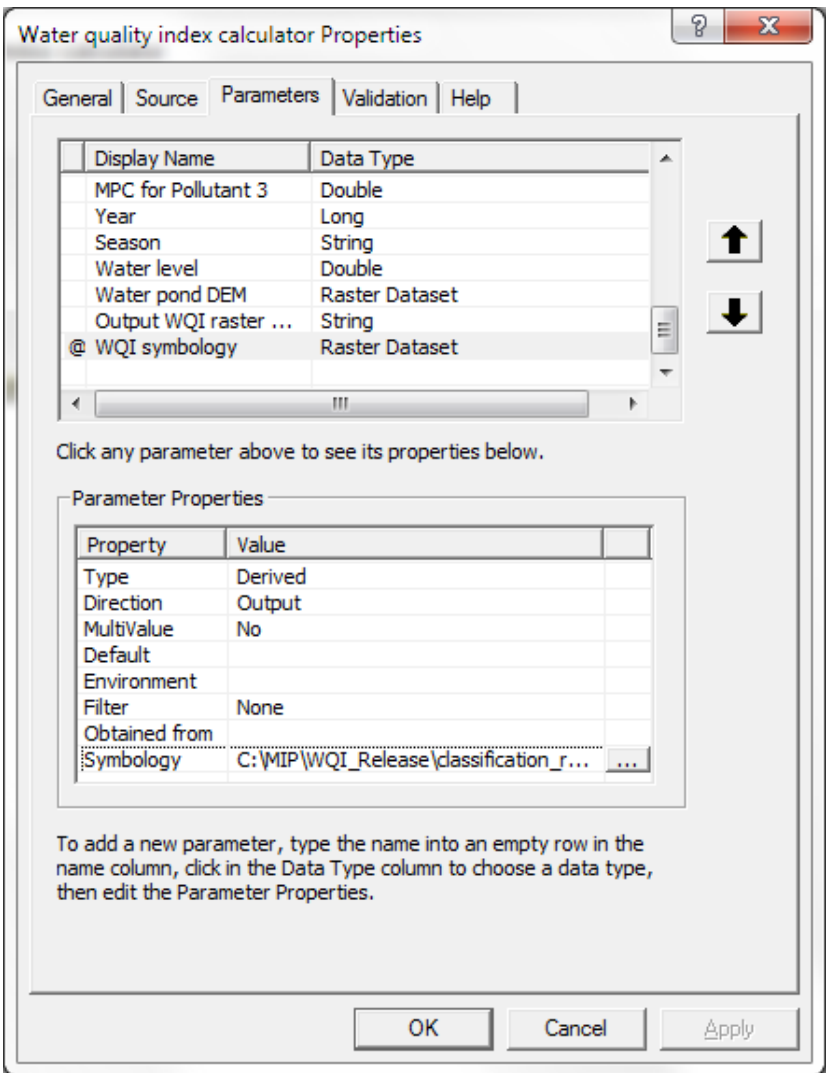

Figure 5-9: The WQI tool properties dialog window GUI.

There is an option to save a source table that was used for WQI calculation and interpolation (Figure 5-10). This table gives an ability to check interpolation source data for validity check, reporting, etc. The default value is No.

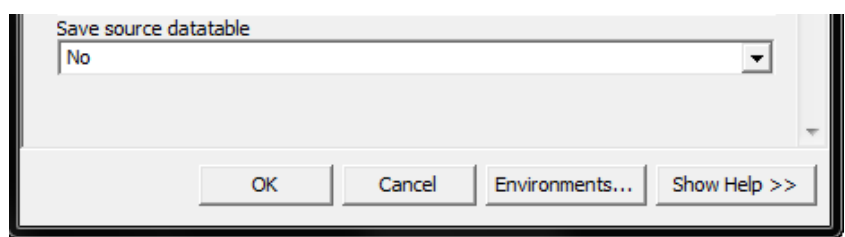

Figure 5-10: The input view of save a source table parameter.

The Python code for this option:

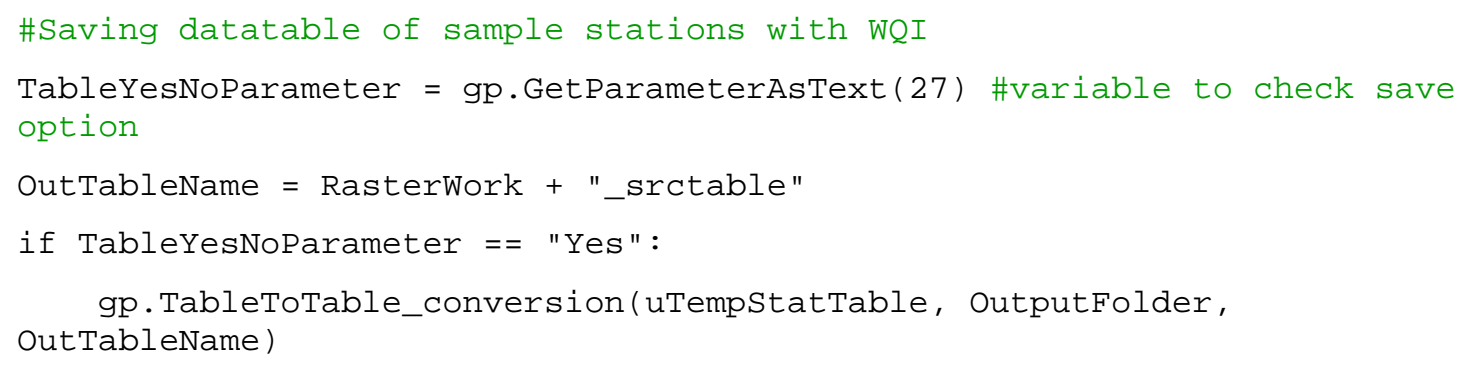




\section{Chapter 6 - Results and Analysis}

This chapter overviews the project's outcome: the geodatabase design and the toolset issues. The decisions made during project evaluation and possibility of application for different study areas are also analyzed

\subsection{The Geodatabase and the Water Quality Index tool}

As discussed before, the database structure was offered by the client. This structure required two main functions: to store water sample analysis results and field data and to support easy and fast editing through the ArcGIS ArcMap functions.

Unfortunately, this approach in geodatabase design did not maintain the normalization rules and did not cover whole process of environmental monitoring of the client's study area. It covered only part that support the water quality assessment, including water quality index calculation. It was enough for the current project evaluation. But as soon the client will improve the GIS framework, the geodatabase structure will be changed and it will be necessary to make changes in the toolset coding.

The WQI tool was created in ESRI ArcGIS geoprocessing script environment using Python as a programming language. This approach had both strengths and weaknesses. Also there were several possible ways to implement the WQI formula calculation in ArcGIS environment: ModelBuilder, ArcObject or geoscripting.

ModelBuilder is an ESRI ArcGIS application in which it has been possible to create, edit, and manage step by step processes - models. The ModelBuilder approach usually suits for environmental modeling sphere, but it is still limited in flexibility. And this point was crucial for the project.

ArcObject is a programming interface of ArcGIS applications. It allows to customize ArcGIS or to create an application for a certain purpose. The ArcObject method was most flexible; but for maintaining of the ArcObject product was necessary to have strong programming skill that the client personnel did not have.

Python is OpenSource programming language that integrated into ArcGIS environment. It is free to use and that was really good for the client's small research group with the very limited budget. But absence of professional technical support force developers to spend more time to maintain issues during coding process.

The combination of the Python and geoprocessing allowed to create the WQI tool for ArcGIS environment using geotools from ArcGIS Toolbox well known by the client's personnel. This approach gave clear, understandable, flexible and easy to maintain the WQI toolset. The weakness of this approach was a limitation dedicated to the general functional limitation of the geotools.

\subsection{Tool Application}

It was mentioned before that the both geodatabase design and the tool structure were customized for the one defined water object - Kuyalnik Liman. And the attempt to implement the results of the current project to any other water object might raise a necessity of the toolset and geodatabase modification. 
The Kuyalnik Liman's geodatabase and the WQI toolset had services fields that were mandatory for calculation, but might vary for different water objects. The possibility of change for these parameters embedded in the use and programming environments of ArcGIS, geoprocessing and Python.

The input tabled data of laboratory water samples results (list of measured pollutants with their concentration) had the mandatory service fields for the WQI calculation: "year" for sampling year, "season" for sampling season, "pointkind" for a sample affiliation: to water area of water pond ("a") or to water network ("w"), "n_point" as a name of the water sampling station. The values for "year" and "season" entered by the graphic user interface (Figure 6-1).

\section{Figure 6-1: Year and season input in the WQI toolset GUI}

The all mentioned above service fields might be corrected only through the Python code:

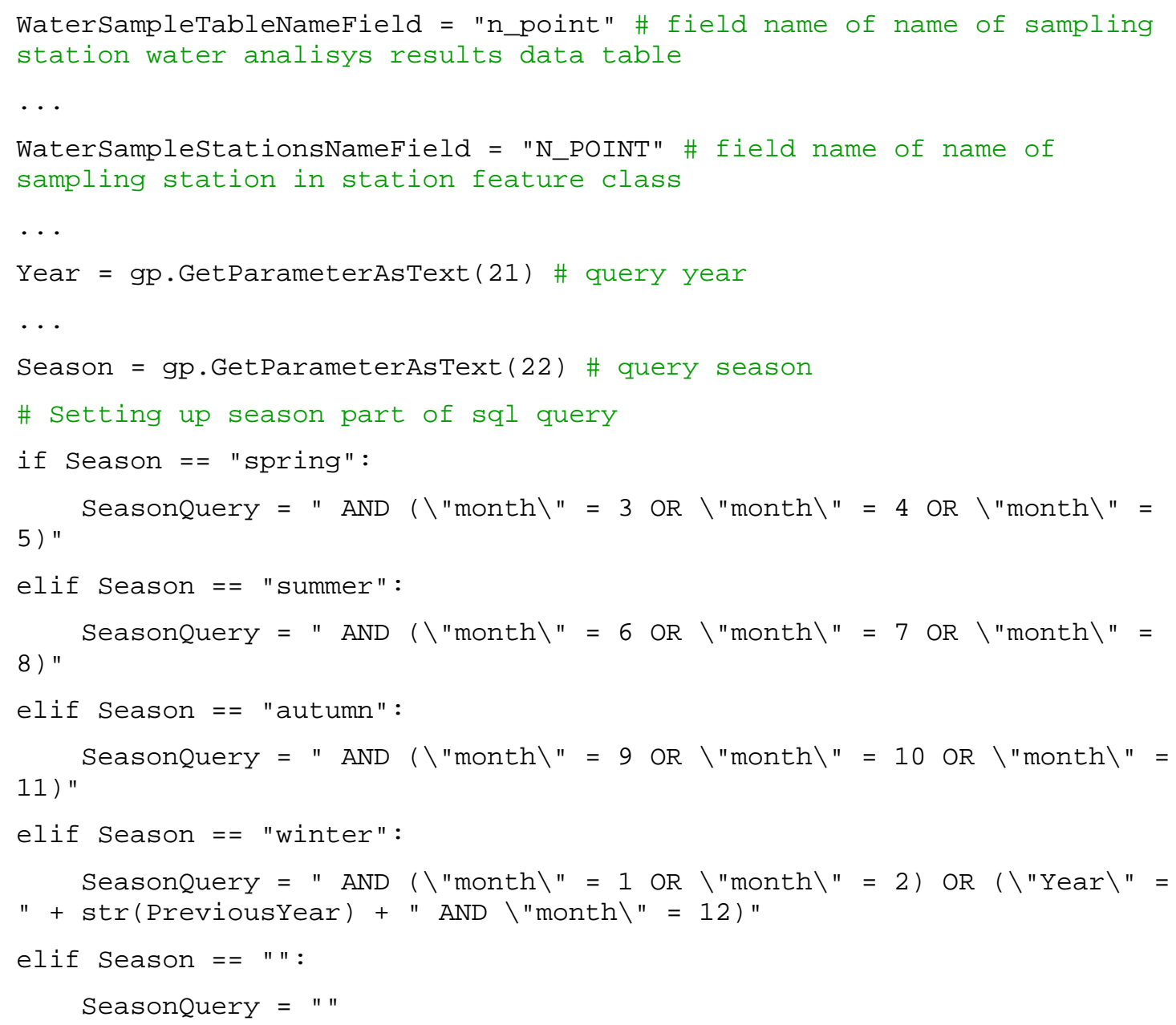


\# Whole sql query for a making query table

SQLQuery = WaterParameterQuery + "\"pointkind \" = 'a' AND \"Year \" = " $+\operatorname{str}($ Year $)+$ SeasonQuery

So the preapplication data processing should consist of two parts: geodatabase preparation in ArcGIS environment and the toolset Python coding correction.

Besides data organization issues there was a challenge related to data processing. The WQI toolset used the inverse distance weighted (IDW) method of interpolation for representation of WQI spatial distribution of Kuyalnik Liman. This method was offered by the client and applied for Kuyalnik Liman. For the implementation of this method to any other water pond, it is necessary to have a foundation for using an IDW interpolation method. For any other interpolation method the toolset Python coding might be changed:

\# Interpolation of WQI between sample stations and inside Extent

gp.Idw_sa("WaterSampleStationsTemp", string.replace(uTempStatTable, TempFolder +"/"," ) + ":WQI", TempFolder + "/" + RasterTemp, CellSize) 



\section{Chapter 7 - Conclusions and Future Projects}

\subsection{Conclusions}

This project provided the GIS framework (geodatabase and water quality index mapping tool) to support of water quality assessment as a part of environmental monitoring conducted by the client's organization.

The goals were achieved in this project by meeting the following objectives:

- the client received a GIS solution that could support the environmental monitoring process of Kuyalnik Liman in terms of mapping water quality

- the client got a WQI tool that automates manual routine calculation and provides a map in a raster format of a spatial distribution of WQI throughout the liman water area; the shoreline of the obtained raster shows the water level for the research time period of WQI calculation

- the calculation method was applicable to the area of interest and spread in academic and administrative community in Ukraine

For water quality assessment was chosen water quality index (WQI) method. The advantages of this method are: it is a standard approach for water quality assessment, it has meaningful water classification, and its output rating is understandable for nonspecialists.

Nature conservation organizations, both administrative and research oriented, use various formulas to calculate WQI. The quality index calculation methodology depends mainly on state affiliation, geographic location of water bodies, type of water use, chemical, and biological factors. Because of its applicability to Kuyalnik Liman and popularity in Ukraine, the method of hydro-chemical index proposed by State Committee of Hydrometeorology of the USSR (1986) was chosen as the theoretical base for this project. Currently it is the commonly used method of WQI determination in Ukraine. It represents an average fraction of limits exceeding six parameters. These might be water parameters: such biological oxygen demand, dissolved oxygen, $\mathrm{pH}$ and/or water pollutants that are specific for study area.

The ESRI software was a standard GIS framework for the client, so the WQI mapping tool was intended to use in ArcGIS environment as a Toolbox toolset. ESRI geodatabase was used as storage for input data. Python language was used as a programming environment. It is opensource language and that is very good because of limited budget of client's research organizations.

Water monitoring stations, bathymetry data of Kuyalnik Liman and water attributes are stored in ESRI File geodatabase. This database format was chosen as scalable and speedy choice for a small group of the client's users and because this kind of geodatabase allows storing rasters and has improved editing model. The input for the WQI tool was preprocessed from rough data. The water monitoring stations layer was represented by point feature class and it located the disposition of 18 water sampling stations through the liman area. This data was collected using handheld GARMIN GPS devices during field work. The bathymetry data of Kuyalnik Liman was based on a field survey that was conducted by Ukrainian Research Institution of Balneology in 1975. The four paper maps from the report represented the network of depth measurements of Kuyalnik Liman. The 
maps contained the point data with elevation marked in Baltic Elevation System and three isolines of depth in BES of Kuyalnik Liman. These maps were scanned, projected at WGS 1984 UTM Zone 36N projection and digitized. From the obtained vector data mentioned bathymetry raster of Kuyalnik Liman was created.

There were three main blocks in tool workflow: water quality index calculation, interpolation through the study area, and a creation of outline of Kuyalnik Liman. Water quality index calculation was an implementation of the mentioned WQI formula with Python language. The formula used values of six pollutants or water parameters and their maximum permissible concentrations. The interpolation block provided spatial interpolation through the study area. For this the inverse distance weighted (IDW) method was used. The third block was responsible to outline the current water level of spatial distribution of water quality index raster on basis of bathymetry data. Also there was a possibility to inherit a classification symbology from a reference layer. This function worked only for ArcMap environment. The water quality index toolset was represented by regular ArcGIS GUI form for geoprocessing tools. The result data was a spatial distribution of water quality index through Kuyalnik Liman in ArcGIS raster format.

\subsection{Future projects}

The WQI tool was created as a GIS support for water quality assessment of Kuyalnik Liman as an analysis basement for administrative and natural management decision making support. There are few related topics that might be used for future projects: web resource of water quality or GIS framework for environment monitoring with set of water quality tools.

\subsubsection{Web resource}

The web resource should provide to user current situation of environmental condition of water of Kuyalnik Liman or any other water body.

The mapping resource should be based on map of hydro-chemical index of water quality (WQI) and maps of separate water pollutants. The calculation of WQI might be based on the method proposed by State Committee of Hydrometeorology of the USSR (1986) or any other methodologies of water quality index calculation. The example of simple water quality web resource for Kuyalnik Liman is shown at Figure 7-1. 


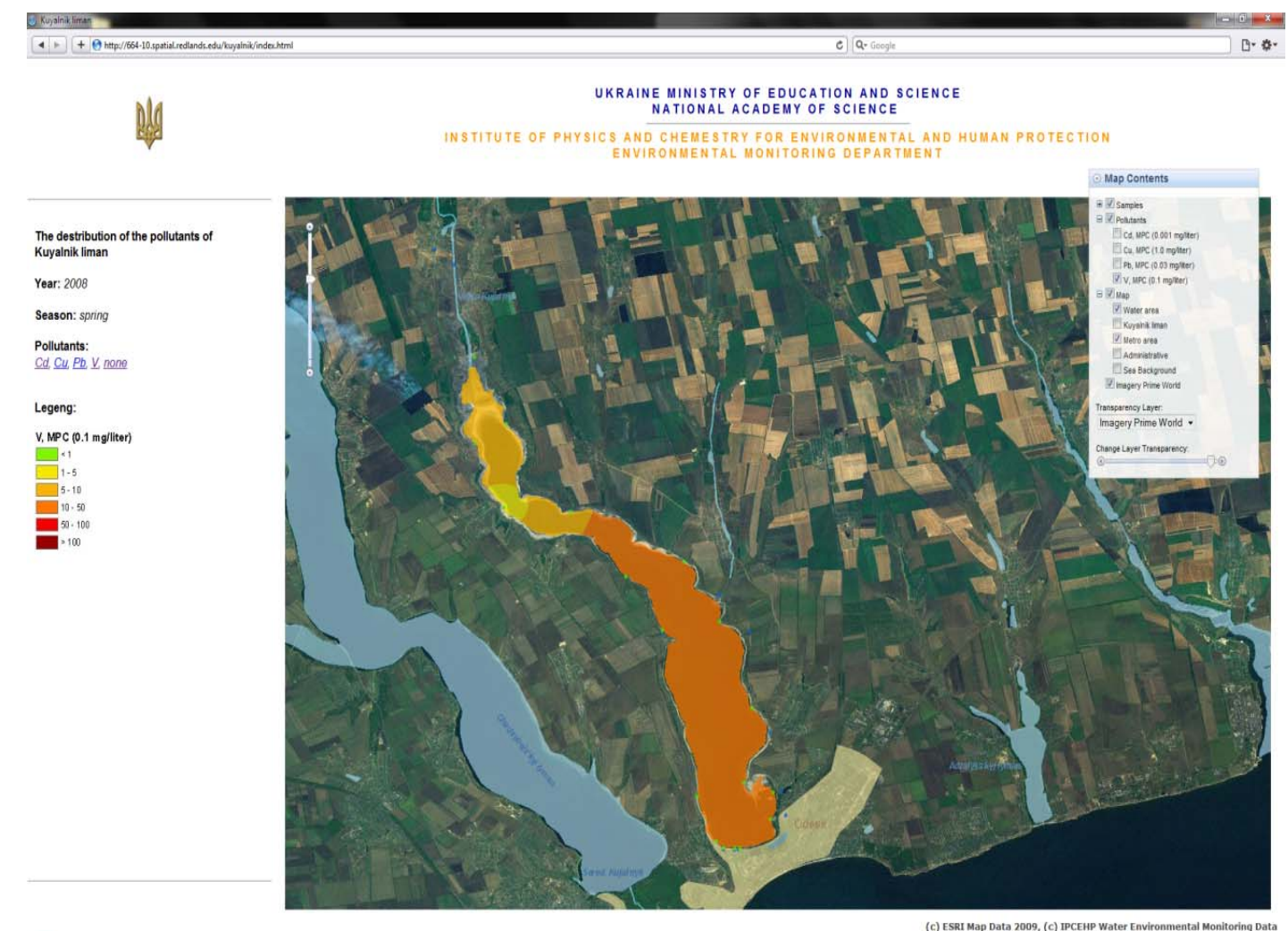

Figure 7-1: The example of water quality web resource for Kuyalnik Liman.

The minimal functionality of the web resource:

- operation functions: zoom in/out, zoom to selected area, table of content with ability switching layers on/off

- query functions: temporal querying by year and/or seasons, querying by pollutants or water quality indices, spatial querying by water monitoring stations

- mapping function: map creation on the basis of query, output map print

- report function: report creation on the basis of query, report print

The web resource might serve as a resource of up-to-date information of environmental condition of Kuyalnik Liman.

\subsubsection{GIS framework for water quality assessment with set of water quality tools}

The proposed project should include geodatabase design with using of normalization rules and set of tools for water quality assessment. These tools might be based on both hydro-chemical and hydro-biological parameters. For example, Shitiokov et al. (2003) proposed several methods of WQI calculation:

Based only on hydro-chemical variables:

- Parameter of chemical water pollution, calculated on the basis exceeding limits of 10 water parameters

- Combinatorial index of pollution, based on limits exceeding, multiplicity and its frequency 
- Method from the Science Research Institution for Hygiene of F.F. Erisman, that takes into account exceeding levels of chemical, microbe, and organoleptic parameters

And classification on the basis of hydro-biological parameters:

- System of water quality classification by Bylinkina A.A. and Drachev S. M.

This GIS framework should cover the whole process of environmental monitoring of the client's study area to support all steps of water quality assessment. 


\section{Works Cited}

Bolstad, P. (2008). GIS Fundamentals. A First Text on Geographic Information Systems. Third Edition. White Bear Lake, MN: Eider Press.

Cabinet of Ministry of Ukraine (1996). Enactment № 1499 from December 11, 1996. Approving of the list of water bodies classified as medical. Kiev: Cabinet of Ministry of Ukraine

Canadian Council of Ministers of the Environment (2001). Canadian water quality guidelines for the protection of aquatic life: CCME Water Quality Index 1.0, Technical Report. Winnipeg: Canadian Council of Ministers of the Environment

Childs, C. (2009). The Top Nine Reasons to Use a File Geodatabase. Arc User. Spring 2009. Retrieved May 28, 2010, from http://www.esri.com/news/arcuser/0309/files/9reasons.pdf

Cude, C. G. (2001). Oregon Water Quality Index: A tool for Evaluating Water Quality Management Effectiveness. Journal of the American Water Resources Association, 37(1), 125-137.

ESRI (2010). ArcGIS Desktop 9.3 Help: Topo to Raster. May 31, 2010, http://webhelp.esri.com/arcgisdesktop/9.3/index.cfm?id=6277\&pid=6268\&topicn ame $=$ Topo to Raster

Hambright, K. D., Parparov, A. \& Berman, T. (2000). Indices of water quality for sustainable management and conservation of an arid region lake, Lake Kinneret (Sea of Galilee), Israel. Aquatic Conservation: Marine and Freshwater Ecosystems, (10), 393-406.

Kurakina, N. I., Emelyanova V. N., Korobeynikov S. A. \& Nikanorova E. S. (2006). Spatial modeling of pollution of water objects. ArcReview, (36), 4-7.

Maidment, D. R. (2002). Arc Hydro. GIS for Water Resources. Redlands, CA: ESRI Press.

Shitiokov V. K., Rozenberg G. S. \& Zinchenko T. D. (2003). Quantitative hydroecology: methods of system identification. October 4, 2009, http://www.ievbran.ru/Kiril/Library/Book1/content0/content0.htm\#Ref

Srinivasan, R., Arnold, J. G. (1993). Basin scale water quality modeling using GIS. Application of Advanced Information Technologies: Effective Management of Natural Resources, 475-484.

State Committee of Hydrometeorology of USSR (1986). Temporary methodological instructions of complex estimation of quality of surface and sea water. Approved by State Committee of Hydrometeorology of USSR 22.09.1986 №250-1163. M: State Committee of Hydrometeorology.

Stoner, J. D. (1978) Water-Quality Indices for Specific Water Uses. Geological Survey circular 770. VA: US Geological Survey.

Timchenko V.M. (1990) Ecohydrological research of North-West Black Sea Littoral Limans. - Kiev: Naukova Dumka.

UkrRIbalneology (1975). The detailed exploration and calculation of reserve of silt mud of Kuyalnik Liman. The report of UkrRIbalneology (1975). Odessa: Archive of UkrRIbalneology.

United States Environmental Protection Agency (2009). October 4, 2009, http://www.epa.gov/waterscience/models/. 
Wright, D. J., Blongewicz, M.J., Halpin, P. N. \& Breman, J. (2007). Arc Marine. GIS for a Blue Planet. Redlands, CA: ESRI Press.

Zhang, Bo (2008). A study of GIS-SD based temporal-spatial modeling of water quality in water pollution accidents. The International Archives of the Photogrammetry, Remote Sensing and Spatial Information Sciences, (XXXVII. Part B2), 155-160. 


\section{Appendix A. The tables of the geodatabase structure classes}

Table A-1. Table of water samples parameters.

\begin{tabular}{|c|c|c|c|c|}
\hline \multicolumn{5}{|c|}{ Alias $\quad$ Water samples parameters } \\
\hline \multicolumn{5}{|l|}{ Dataset Type Table } \\
\hline Field Name & Alias Name & Type & Length & Null \\
\hline OBJECTID & OBJECTID & OID & 4 & No \\
\hline month & Month & Small Integer & 2 & Yes \\
\hline season & Season & String & 10 & Yes \\
\hline year & Year & Small Integer & 2 & Yes \\
\hline pointkind & Type of sample & String & 1 & Yes \\
\hline susp_substance & Suspended substances, g/l & Single & 4 & Yes \\
\hline transparency & Transparency, $\mathrm{cm}$ & Single & 4 & Yes \\
\hline color & Color, grad & Single & 4 & Yes \\
\hline $\mathrm{pH}$ & $\mathrm{pH}$ & Single & 4 & Yes \\
\hline chlorides & Chlorides, mg/1 & Single & 4 & Yes \\
\hline sulphates & Sulphates, mg/1 & Single & 4 & Yes \\
\hline sulphides & Sulphides, mg/1 & Single & 4 & Yes \\
\hline hydr_carbonates & Hydrocarbonates, mg-ekv/l & Single & 4 & Yes \\
\hline $\mathrm{Na}$ & $\mathrm{Na}, \mathrm{mg} / \mathrm{l}$ & Single & 4 & Yes \\
\hline K & $\mathrm{K}, \mathrm{mg} / \mathrm{l}$ & Single & 4 & Yes \\
\hline $\mathrm{Ca}$ & $\mathrm{Ca}, \mathrm{mg} / 1$ & Single & 4 & Yes \\
\hline $\mathrm{Mg}$ & $\mathrm{Mg}, \mathrm{mg} / \mathrm{l}$ & Single & 4 & Yes \\
\hline hardness & Hardness, mg-ekv/l & Single & 4 & Yes \\
\hline solid_res & Solid residue, $\mathrm{g} / 1$ & Single & 4 & Yes \\
\hline salinity & Salinity, promille & Single & 4 & Yes \\
\hline chem_oxygen_demand & Chemical oxygen demand, mg/l & Single & 4 & Yes \\
\hline biochem_oxygen_demand & Biochemical oxygen demand, mg/l & Single & 4 & Yes \\
\hline dissolved_oxygen & Dissolved oxygen, $\mathrm{mg} / \mathrm{l}$ & Single & 4 & Yes \\
\hline nitrates & Nitrates, $\mathrm{mg} / \mathrm{l}$ & Single & 4 & Yes \\
\hline nitrites & Nitrites, mg/1 & Single & 4 & Yes \\
\hline $\mathrm{N}$ ammonium & $\mathrm{N}$ ammonium, mg/l & Single & 4 & Yes \\
\hline phosphates & Phosphates, mg/l & Single & 4 & Yes \\
\hline $\mathrm{SiO} 2$ & $\mathrm{SiO} 2, \mathrm{~g} / 1$ & Single & 4 & Yes \\
\hline phenol & Phenols, mg/l & Single & 4 & Yes \\
\hline formaldehyde & Formaldehyde, mg/1 & Single & 4 & Yes \\
\hline oil_chloroform & Oil products (chl), mg/l & Single & 4 & Yes \\
\hline oil_hexan & Oil products (hex), mg/l & Single & 4 & Yes \\
\hline $\mathrm{Al}^{-}$ & $\mathrm{Al}, \mathrm{mg} / \mathrm{l}$ & Single & 4 & Yes \\
\hline $\mathrm{Mn}$ & $\mathrm{Mn}, \mathrm{mg} / \mathrm{l}$ & Single & 4 & Yes \\
\hline $\mathrm{Cu}$ & $\mathrm{Cu}, \mathrm{mg} / \mathrm{l}$ & Single & 4 & Yes \\
\hline $\mathrm{Pb}$ & $\mathrm{Pb}, \mathrm{mg} / \mathrm{l}$ & Single & 4 & Yes \\
\hline $\mathrm{Cd}$ & $\mathrm{Cd}, \mathrm{mg} / 1$ & Single & 4 & Yes \\
\hline $\mathrm{Cr}$ & $\mathrm{Cr}, \mathrm{mg} / \mathrm{l}$ & Single & 4 & Yes \\
\hline V & $\mathrm{V}, \mathrm{mg} / \mathrm{l}$ & Single & 4 & Yes \\
\hline $\mathrm{Fe}$ & $\mathrm{Fe}, \mathrm{mg} / \mathrm{l}$ & Single & 4 & Yes \\
\hline $\mathrm{Zn}$ & $\mathrm{Zn}$ & Single & 4 & Yes \\
\hline N_min & $\mathrm{N}$ mineral, mg/l & Single & 4 & Yes \\
\hline oxygenation & Oxygenation, $\%$ & Single & 4 & Yes \\
\hline
\end{tabular}




$\begin{array}{lllll}\begin{array}{l}\text { Oil_mikran } \\ \text { day }\end{array} & \text { Oil products (mikran), mg/l } & \text { Single } & 4 & \text { Yes } \\ \text { fluorides } & \text { Day } & \text { Small Integer } & 2 & \text { Yes } \\ \text { borate } & \text { Fluorides, mg/l } & \text { Single } & 4 & \text { Yes } \\ \text { bromide } & \text { Borate, } \mathrm{mg} / \mathrm{l} & \text { Single } & 4 & \text { Yes } \\ \text { chlorophyll } & \text { Bromide, } \mathrm{mg} / \mathrm{l} & \text { Single } & 4 & \text { Yes } \\ \text { salt_content } & \text { Chlorophyll "a", mkg/l } & \text { Single } & 4 & \text { Yes } \\ \text { sampl_date } & \text { Salt content, g/l } & \text { Single } & 4 & \text { Yes } \\ \text { w_temp } & \text { Date of water sampling } & \text { Date } & 8 & \text { Yes } \\ \text { n_point } & \text { Water temperature, C } & \text { Small Integer } & 2 & \text { Yes } \\ \text { Domains } & \text { Name } & \text { String } & 50 & \text { Yes } \\ \text { month } & & & & \\ \text { season } & & & & \end{array}$

Table A-2. Table of maximum permissible concentrations.

\begin{tabular}{|c|c|c|c|c|}
\hline \multirow{2}{*}{$\begin{array}{ll}\text { Alias } & \text { Maxim } \\
\text { Dataset Type } & \text { Table }\end{array}$} & \multirow[b]{3}{*}{ Alias Name } & \multirow[b]{3}{*}{ Type } & \multirow[b]{3}{*}{ Length } & \multirow[b]{3}{*}{ Nul } \\
\hline & & & & \\
\hline Field Name & & & & \\
\hline OBJECTID & OBJECTID & OID & 4 & No \\
\hline susp_substance & Suspended substances, g/l & Single & 4 & Yes \\
\hline transparency & Transparency, cm & Single & 4 & Yes \\
\hline color & Color, grad & Single & 4 & Yes \\
\hline $\mathrm{pH}$ & $\mathrm{pH}$ & Single & 4 & Yes \\
\hline chlorides & Chlorides, mg/l & Single & 4 & Yes \\
\hline sulphates & Sulphates, mg/l & Single & 4 & Yes \\
\hline sulphides & Sulphides, mg/1 & Single & 4 & Yes \\
\hline hydr_carbonates & Hydrocarbonates, mg-ekv/l & Single & 4 & Yes \\
\hline $\mathrm{Na}$ & $\mathrm{Na}, \mathrm{mg} / \mathrm{l}$ & Single & 4 & Yes \\
\hline K & $\mathrm{K}, \mathrm{mg} / \mathrm{l}$ & Single & 4 & Yes \\
\hline $\mathrm{Ca}$ & $\mathrm{Ca}, \mathrm{mg} / 1$ & Single & 4 & Yes \\
\hline $\mathrm{Mg}$ & $\mathrm{Mg}, \mathrm{mg} / 1$ & Single & 4 & Yes \\
\hline hardness & Hardness, mg-ekv/1 & Single & 4 & Yes \\
\hline solid_res & Solid residue, $\mathrm{g} / \mathrm{l}$ & Single & 4 & Yes \\
\hline salinity & Salinity, promille & Single & 4 & Yes \\
\hline chem_oxygen_demand & Chemical oxygen demand, mg/l & Single & 4 & Yes \\
\hline biochem_oxygen_demand & Biochemical oxygen demand, mg/l & Single & 4 & Yes \\
\hline dissolved_oxygen & Dissolved oxygen, $\mathrm{mg} / \mathrm{l}$ & Single & 4 & Yes \\
\hline nitrates & Nitrates, $\mathrm{mg} / \mathrm{l}$ & Single & 4 & Yes \\
\hline nitrites & Nitrites, mg/1 & Single & 4 & Yes \\
\hline N_ammonium & $\mathrm{N}$ ammonium, mg/l & Single & 4 & Yes \\
\hline phosphates & Phosphates, mg/l & Single & 4 & Yes \\
\hline $\mathrm{SiO} 2$ & $\mathrm{SiO} 2, \mathrm{~g} / 1$ & Single & 4 & Yes \\
\hline phenol & Phenols, mg/l & Single & 4 & Yes \\
\hline formaldehyde & Formaldehyde, mg/l & Single & 4 & Yes \\
\hline oil_chloroform & Oil products (chl), mg/l & Single & 4 & Yes \\
\hline oil_hexan & Oil products (hex), mg/l & Single & 4 & Yes \\
\hline $\mathrm{Al}^{-}$ & $\mathrm{Al}, \mathrm{mg} / \mathrm{l}$ & Single & 4 & Yes \\
\hline $\mathrm{Mn}$ & $\mathrm{Mn}, \mathrm{mg} / 1$ & Single & 4 & Yes \\
\hline $\mathrm{Cu}$ & $\mathrm{Cu}, \mathrm{mg} / \mathrm{l}$ & Single & 4 & Yes \\
\hline $\mathrm{Pb}$ & $\mathrm{Pb}, \mathrm{mg} / \mathrm{l}$ & Single & 4 & Yes \\
\hline $\mathrm{Cd}$ & $\mathrm{Cd}, \mathrm{mg} / 1$ & Single & 4 & Yes \\
\hline $\mathrm{Cr}$ & $\mathrm{Cr}, \mathrm{mg} / \mathrm{l}$ & Single & 4 & Yes \\
\hline
\end{tabular}




$\begin{array}{lllll}\text { V } & \text { V }, \mathrm{mg} / \mathrm{l} & \text { Single } & 4 & \text { Yes } \\ \text { Fe } & \text { Fe, mg/l } & \text { Single } & 4 & \text { Yes } \\ \text { Zn } & \text { Zn } & \text { Single } & 4 & \text { Yes } \\ \text { N_min } & \text { N mineral, , mg/l } & \text { Single } & 4 & \text { Yes } \\ \text { oxygenation } & \text { Oxygenation, \% } & \text { Single } & 4 & \text { Yes } \\ \text { Oil_mikran } & \text { Oil products (mikran), mg/l } & \text { Single } & 4 & \text { Yes } \\ \text { fluorides } & \text { Fluorides, }, \mathrm{mg} / 1 & \text { Single } & 4 & \text { Yes } \\ \text { borate } & \text { Borate, mg/l } & \text { Single } & 4 & \text { Yes } \\ \text { bromide } & \text { Bromide, mg/l } & \text { Single } & 4 & \text { Yes } \\ \text { chlorophyll } & \text { Chlorophyll "a", mkg/1 } & \text { Single } & 4 & \text { Yes } \\ \text { salt_content } & \text { Salt content, g/l } & \text { Single } & 4 & \text { Yes } \\ \text { type_wat_use } & \text { Type of water use } & \text { String } & 10 & \text { Yes } \\ \text { iss_agency } & \text { Issued agency } & \text { String } & 10 & \text { Yes } \\ \text { Domains } & & & & \\ \text { type_wat_use } & & & & \\ \text { iss_agency } & & & & \end{array}$

Table A-3. Feature class of water monitoring stations.

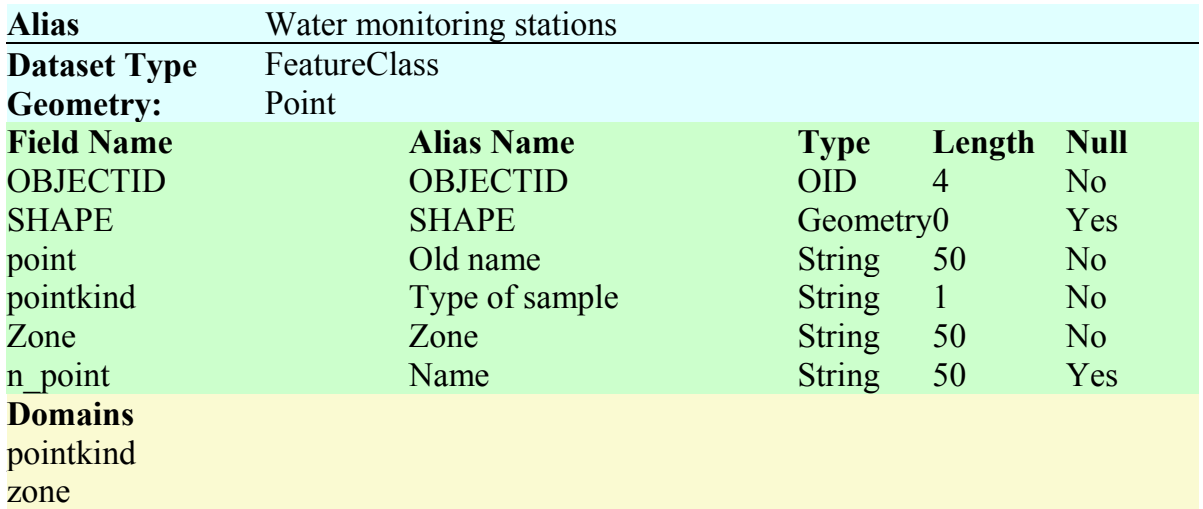

Table A-4. Geodatabase domains.

\begin{tabular}{|c|c|}
\hline Description & The water standards issued agency \\
\hline Domain Type & Coded Value \\
\hline Field Type & String \\
\hline \multicolumn{2}{|l|}{ Domain Members } \\
\hline Name & Value \\
\hline EU & $\mathrm{eu}$ \\
\hline WHO & who \\
\hline Ministry of health of Ukraine & ua \\
\hline \multicolumn{2}{|l|}{ month } \\
\hline Description & Month \\
\hline Domain Type & Coded Value \\
\hline Field Type & Small Integer \\
\hline \multicolumn{2}{|l|}{ Domain Members } \\
\hline Name & Value \\
\hline January & 1 \\
\hline February & 2 \\
\hline March & 3 \\
\hline
\end{tabular}




\begin{tabular}{|c|c|}
\hline April & 4 \\
\hline May & 5 \\
\hline June & 6 \\
\hline July & 7 \\
\hline August & 8 \\
\hline September & 9 \\
\hline October & 10 \\
\hline November & 11 \\
\hline December & 12 \\
\hline \multicolumn{2}{|l|}{ pointkind } \\
\hline Description & The water monitoring station affiliation \\
\hline Domain Type & Coded Value \\
\hline Field Type & String \\
\hline \multicolumn{2}{|l|}{ Domain Members } \\
\hline Name & Value \\
\hline water area & $\mathrm{a}$ \\
\hline water network & $\mathrm{w}$ \\
\hline \multicolumn{2}{|l|}{ season } \\
\hline Description & Season \\
\hline Domain Type & Coded Value \\
\hline Field Type & String \\
\hline \multicolumn{2}{|l|}{ Domain Members } \\
\hline Name & Value \\
\hline Spring & spring \\
\hline Summer & summer \\
\hline Autumn & autumn \\
\hline Winter & winter \\
\hline \multicolumn{2}{|l|}{ type_wat_use } \\
\hline Description & The type of water use \\
\hline Domain Type & Coded Value \\
\hline Field Type & String \\
\hline \multicolumn{2}{|l|}{ Domain Members } \\
\hline Name & Value \\
\hline Drinking water & drnk \\
\hline Recreational water & recr \\
\hline \multicolumn{2}{|l|}{ zone } \\
\hline Description & The water pond zones \\
\hline Domain Type & Coded Value \\
\hline Field Type & String \\
\hline \multicolumn{2}{|l|}{ Domain Members } \\
\hline Name & Value \\
\hline North & north \\
\hline Center & center \\
\hline South & south \\
\hline Water network & water network \\
\hline
\end{tabular}

Table A-5. Relationship class.

Points2Water

Composite No

Cardinality One To Many

Notification None

Attributed No

Origin

Destination 
ObjectClass water_sample_station_disposition $\begin{array}{ll}\text { Key } & \mathrm{n} \text { _point (Origin Primary Key) } \\ \text { Labels } & \text { points }\end{array}$

Rules

\section{Subtype} water_sample_station_disposition

water_sample_results

$\mathrm{n} \_$point (Origin Foreign Key)

water

Origin
Cardinality Subtype

water_sample_results
Destination

Cardinality

M

Table A-6. The specification of the water pond elevation class.

\section{DEM}

Columns and Rows 1248, 1248

Number of Bands 1

Cell size

10,10

Source type continuous

Pixel type floating point

Pixel Depth 32 bit 


\section{Appendix B. The listing of the WQI tool Python code}

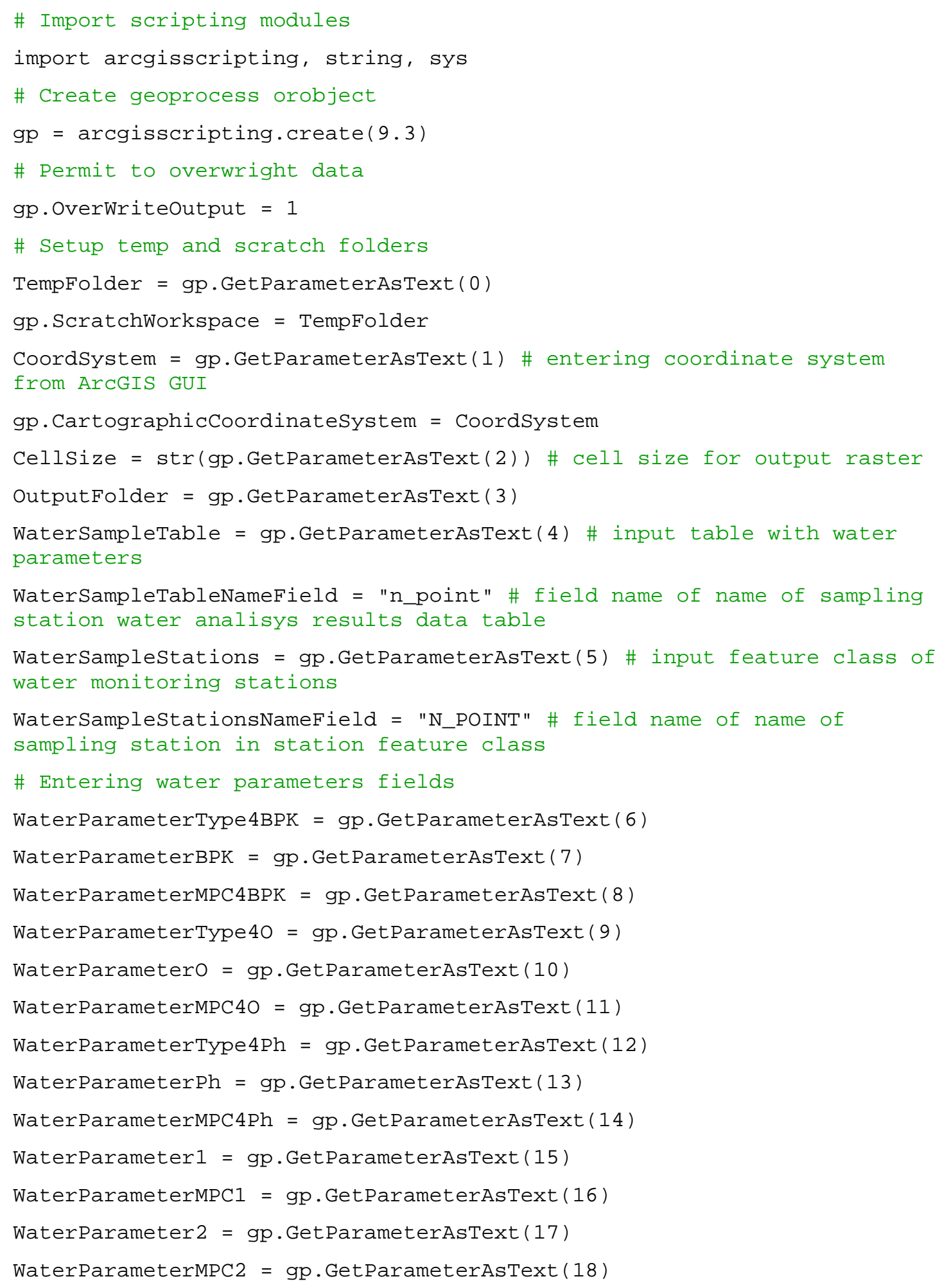




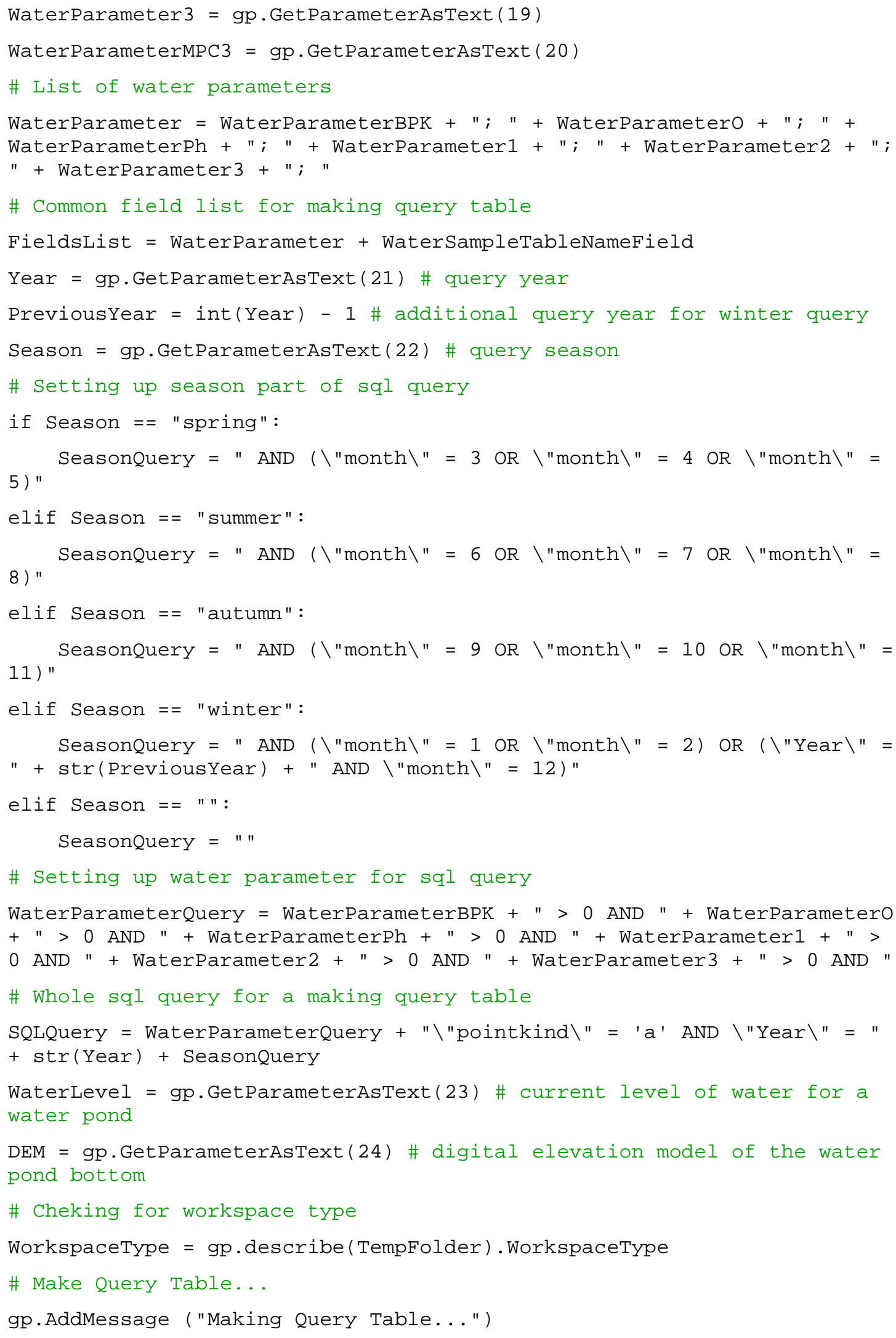




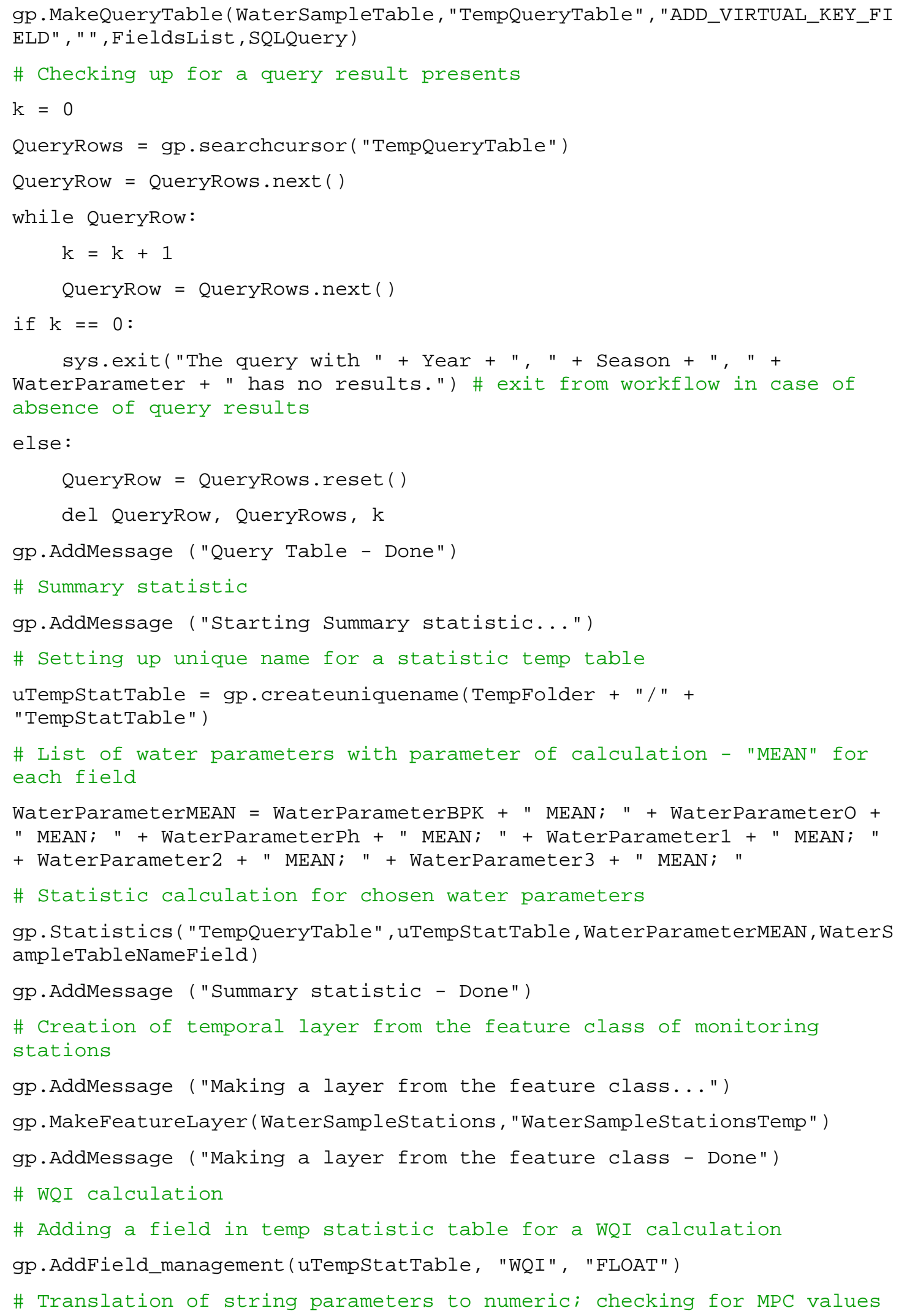




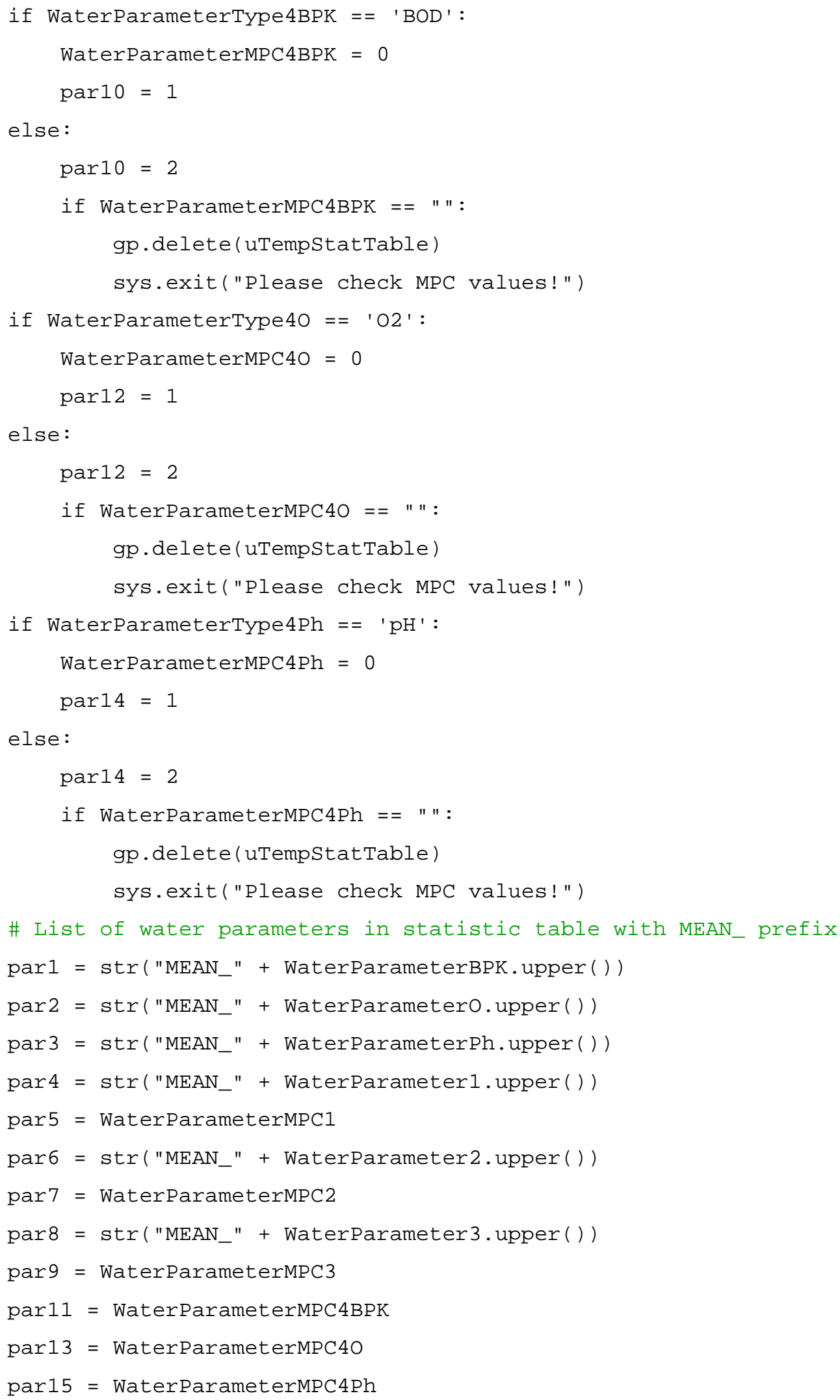


\# Expression for field WQI calculation. Water parameters are limited by 16 symbols

ExpressionWQI $=$

"WQICalculation (\%s, \%s, \%s, \%s, \%s,\%s, \%s, \%s, \%s, \%s, \%s, \%s, \%s, \%s, \%s)" \% ("! " + par1[0:16]+"!", "! " + par2[0:16]+"!", "!" + par3[0:16]+"!", "!" +

par4[0:16]+"!", par5, "!" + par6[0:16]+"!", par7, "!" + par8[0:16]+"!", par9, par10, par11, par12, par13, par14, par15)

\# Codeblock for field calculation. It contains formula for WQI

calculation.

FieldCalcCodeBlock = "def

WQICalculation (WaterParameterBPK, waterParameter0, waterParameterPh, water Parameter1, waterParameterMPC1, waterParameter2, waterParameterMPC2, waterP arameter3, waterParameterMPC3, waterParameterType4BPK, waterParameterMPC4B PK, waterParameterType40, waterParameterMPC40, waterParameterType4Ph, water ParameterMPC4Ph): \n\

if waterParameterType4BPK $==1: \backslash n \backslash$

if float (WaterParameterBPK) $<3: \backslash n \backslash$

bpk = float (WaterParameterBPK) / $3 \backslash n \backslash$

elif float (WaterParameterBPK) $<=15: \backslash n \backslash$

bpk = float (WaterParameterBPK) / 2\n\

elif float (WaterParameterBPK) > 15: \n\

bpk = float (WaterParameterBPK) / $1 \backslash n \backslash$

else: \n\

bpk $=$ float $($ WaterParameterBPK)/float (WaterParameterMPC4BPK) \n\

$\backslash n \backslash$

if WaterParameterType $40==1: \backslash n \backslash$

if float (WaterParameter0) $<1: \backslash n \backslash$

$02=60 \backslash n \backslash$

elif float (WaterParameter0) $<2$ : \n\

$02=50 \backslash n \backslash$

elif float (WaterParameter0) $<3: \backslash n \backslash$

$02=40 \backslash n \backslash$

elif float (WaterParameter 0$)<4: \backslash n \backslash$

$02=30 \backslash n \backslash$

elif float (WaterParametero) $<5: \backslash n \backslash$

$02=20 \backslash n \backslash$

elif float (WaterParameter0) $<6$ : \n\

$02=12 \backslash n \backslash$

elif float (WaterParameter0) $>=6: \backslash n \backslash$

$02=6 \backslash n \backslash$

else: \n\ 


$$
02=\text { float (WaterParameter0)/float (WaterParameterMPC40) \n\ }
$$

$\backslash n \backslash$

if WaterParameterType4Ph == $1: \backslash n \backslash$

$$
\mathrm{ph}=1 \backslash \mathrm{n} \backslash
$$

$9.5: \backslash n \backslash$

$$
\text { if float(WaterParameterPh) < } 5 \text { or float(WaterParameterPh) > }
$$

$$
\mathrm{ph}=20 \backslash \mathrm{n} \backslash
$$

$9: \backslash n \backslash$

$$
\text { elif float(WaterParameterPh) < } 6 \text { or float(WaterParameterPh) > }
$$

$$
\mathrm{ph}=5 \backslash \mathrm{n} \backslash
$$

8.5:\n\

elif float (WaterParameterPh) < 6.5 or float(WaterParameterPh) >

$$
\mathrm{ph}=2 \backslash \mathrm{n} \backslash
$$

else: \n\

$$
\text { ph }=\text { float }(\text { WaterParameterPh }) / \text { float }(\text { WaterParameterMPC4Ph }) \backslash \mathrm{n} \backslash
$$

$\backslash n \backslash$

wqi_par $=$

(bpk+o2+ph+(float (WaterParameter1)/float (WaterParameterMPC1)) + (float (Wa terParameter 2$) / f l o a t($ WaterParameterMPC2) $)+($ float (WaterParameter3)/float $($ WaterParameterMPC3)) ) / 6\n\

return wqi_par"

gp.CalculateField_management(uTempStatTable, "WQI", ExpressionWQI, "PYTHON_9.3", FieldCalcCodeBlock)

\# Process: Add Join...

gp.AddMessage ("Process: Add Join...")

\# Join feature class with sample station disposition and table with WQI calculated

gp.AddJoin_management( "WaterSampleStationsTemp", waterSampleTableNameField, uTempStatTable, waterSamplestationsNameField, "KEEP_COMMON")

gp.AddMessage ("Process: Add Join - Done")

\# Check out ArcGIS Spatial Analyst extension license

gp. CheckoutExtension("Spatial")

\# Process: ContourList

gp.AddMessage ("Process: ContourList...")

\# Setting up unique name for a temp linear contour feature class

uTempContourList $=$ gp. createuniquename $($ TempFolder $+" / "+$

"TempContourList")

\# Temp contour feature class of shoreline of water pond based on current water level

gp.ContourList_sa(DEM, uTempContourList, WaterLevel) 


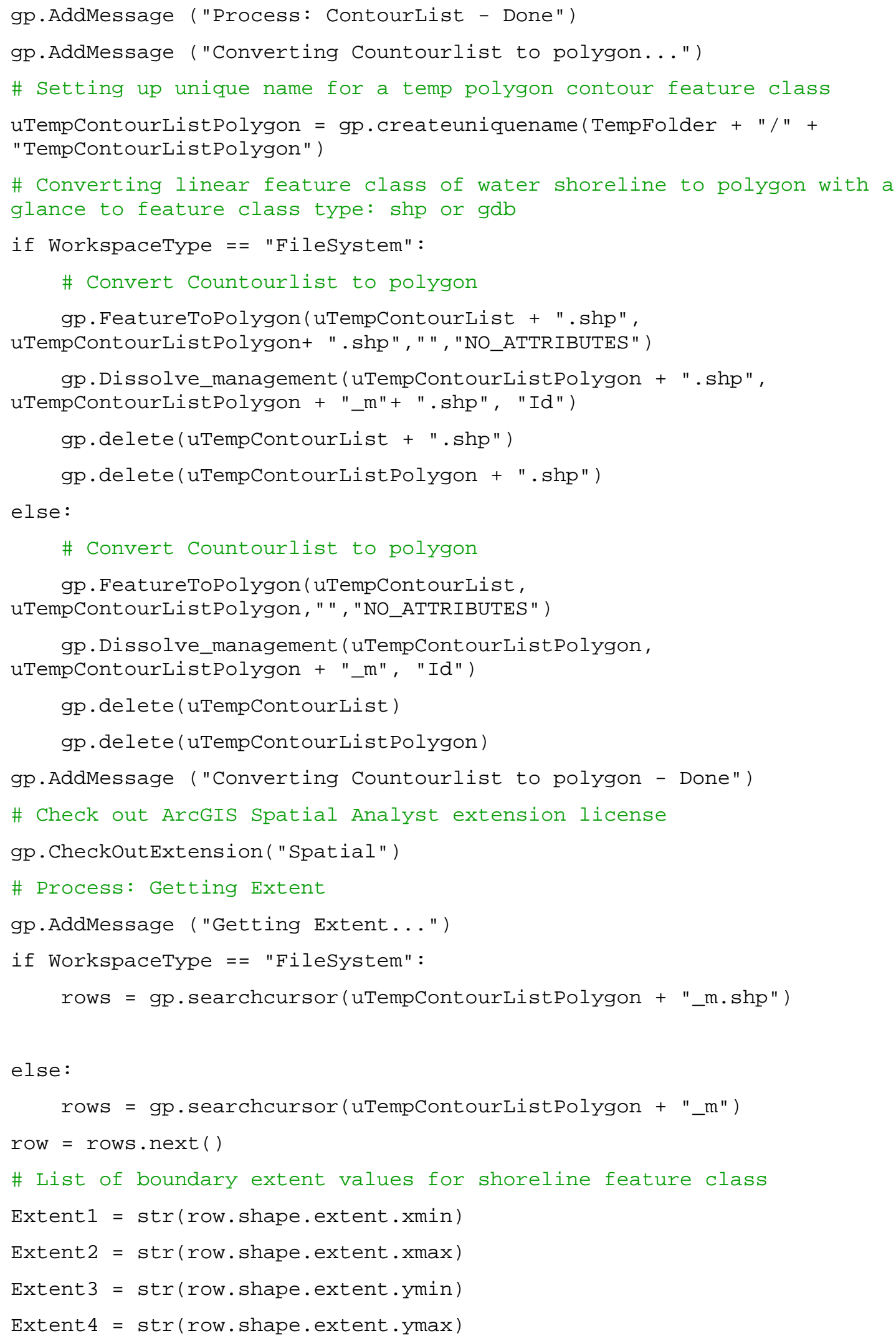




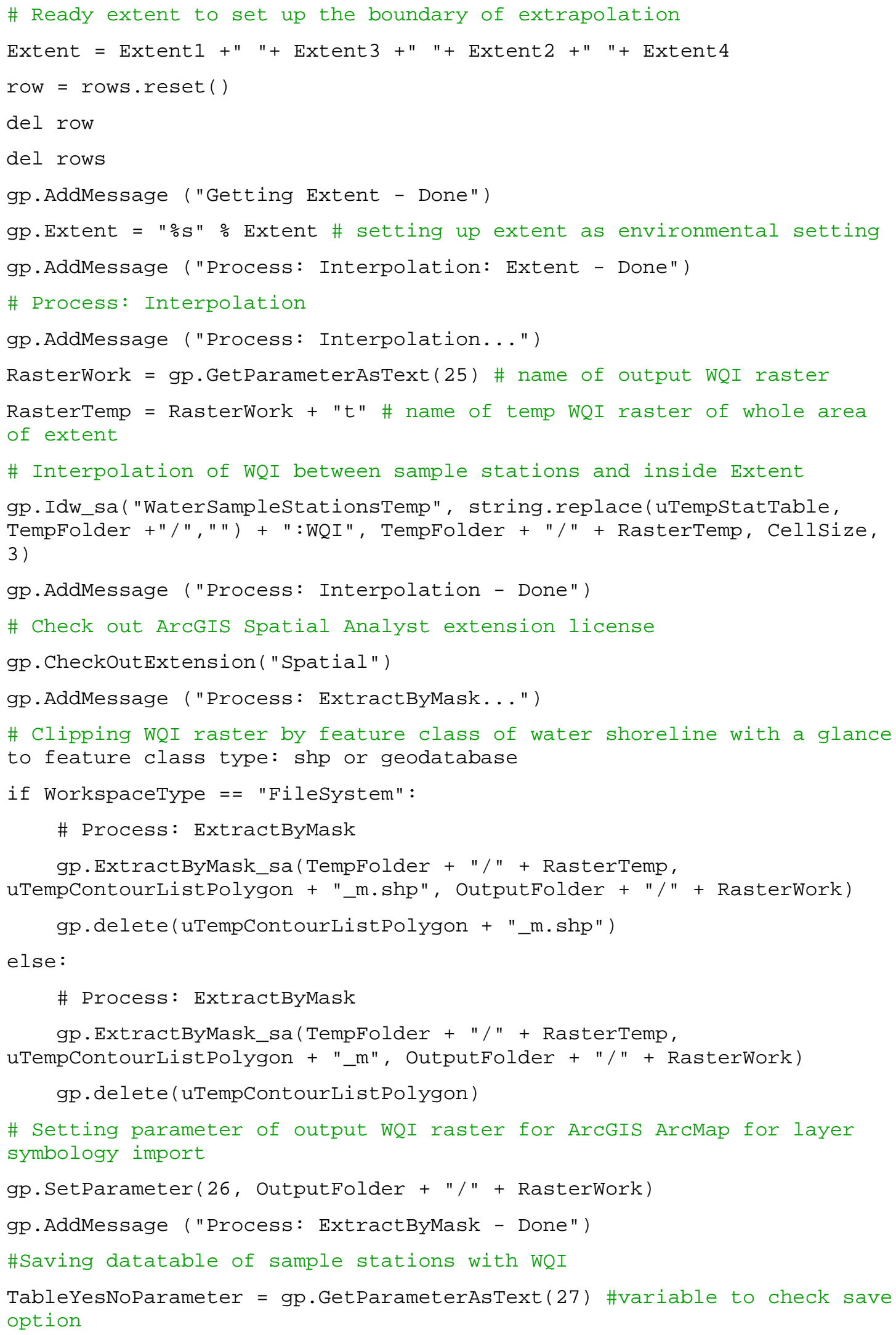


OutTableName $=$ RasterWork + "_srctable"

if TableYesNoParameter $==$ "Yes":

gp.TableToTable_conversion(uTempstatTable, OutputFolder, OutTableName)

\#Free memory \& space

gp.delete(TempFolder + "/" + RasterTemp)

gp.delete (uTempstatTable)

gp.AddMessage ("All done!")

del gp 


\section{Appendix C. The copy of WQI methodology in original (Russian) language}

Гидрохимический индекс загрязения воды (ИЗВ) установлен Госкомгидрометом СССР и относится к категории показателей, наиболее часто используемых для оценки качества водных объектов. Этот индекс является типичным аддитивным коэффициентом и представляет собой среднюю долю превышения ПДК по строго лимитированному числу индивидуальных ингредиентов:

$$
\text { ИЗВ }=\frac{1}{n} * \sum_{i=1}^{n} \frac{C_{i}}{\Pi Д К_{i}}
$$

где:

- $\mathbf{C}_{\mathbf{i}}-$ концентрация компонента (в ряде случаев - значение физикохимического параметра);

- $\mathbf{n}-$ число показателей, используемых для расчета индекса, $\mathbf{n}=6$;

- $\boldsymbol{\Pi L}_{\mathbf{i}}-$ установленная величина норматива для соответствующего типа водного объекта.

Для расчета индекса загрязнения вод для всего множества нормируемых компонентов, включая водородный показатель $\mathrm{pH}$, биологическое потребление кислорода БПК $\mathrm{C}_{\mathrm{i}} /$ ПДК $\mathrm{i}_{\mathrm{i}}$ фактических концентраций к ПДК и полученный список сортируют. ИЗВ рассчитывают строго по шести показателям, имеющим наибольшие значения приведенных концентраций, независимо от того превышают они ПДК или нет.

При расчете ИЗВ для составляющих $\mathrm{C}_{\mathrm{i}} /$ ПДК компонентам применяется ряд следующих условий:

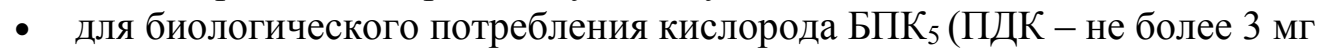
$\mathrm{O}_{2} /$ дм$^{3}$ для водоемов хозяйственно-питьевого водопользования и не более 6 мг $\mathrm{O}_{2} /$ дм $^{3}$ для водоемов хозяйственно-бытового и культурного водопользования) устанавливаются специальные значения нормативов, зависящие от самого значения БПК 5 :

\section{$\underline{\text { Показатель БПК }} \underline{5}_{2} \underline{\mathrm{M \Gamma O}}_{2} \underline{\text { л) }} \quad \underline{\text { Значение норматива (ПДК) }}$}

$\begin{array}{cc}\text { Менее } 3 & 3 \\ \text { От } 3 \text { до 15 } & 2 \\ \text { Свыше } 15 & 1\end{array}$

- концентрация растворенного кислорода нормируется с точностью до наоборот: его содержание в пробе не должно быть ниже 4 мг/дм ${ }^{3}$, поэтому для каждого диапазона концентраций компонента устанавливаются специальные значения слагаемых $\mathrm{C}_{\mathrm{i}} /$ ПДК

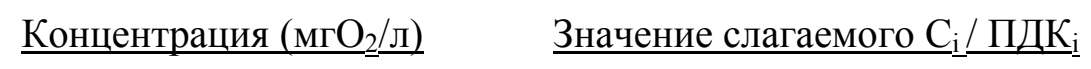

Более или равно 6 
Менее 6 до 5

Менее 5 до 4

Менее 4 до 3

Менее 3 до 2

Менее 2 до 1

Менее 1

- для водородного показателя $\mathrm{pH}$ действующие нормативы для воды водоемов различного назначения регламентируют диапазон допустимых значений в интервале от 6,5 до 8,5, поэтому для каждого сверхнормативного значения pH, выходящего за границы этого диапазона, устанавливаются специальные значения слагаемых $\mathrm{C}_{\mathrm{i}} /$ ПДК

Значения $\mathrm{pH}$ ниже диапазона нормы $(<6.5)$

Менее 6.5 до 6
Значения $\mathrm{pH}$ выше диапазона нормы (>8.5)
Значение слагаемого $\underline{\mathrm{C}_{\mathrm{i}} / \Pi Д \mathrm{~K}_{\mathrm{i}}}$
Менее 6 до 5

\author{
Свыше 8.5 до 9
}

Свыше 9 до 9.5

\section{2}

5

Менее 5

Свыше 9.5

20

В зависимости от величины ИЗВ участки водных объектов подразделяют на классы. Устанавливается требование, чтобы индексы загрязнения воды сравнивались для водных объектов одной биогеохимической провинции и сходного типа, для одного и того же водотока (по течению, во времени, и так далее), а также с учетом фактической водности текущего года.

Классы качества вод в зависимости от значения индекса загрязнения воды:

\section{Воды}

Очень чистые

Чистые

Умеренно загрязненные

Загрязненные

Грязные

Очень грязные

Чрезвычайно грязные
Значения ИЗВ

до 0,2

$0,2-1,0$

$1,0-2,0$

$2,0-4,0$

$4,0-6,0$

$6,0-10,0$

$>10,0$
Классы качества вод

\section{I}

II

III

IV

$\mathrm{V}$

VI

VII 